\title{
Mechanism of Spontaneous Firing in Dorsomedial Suprachiasmatic Nucleus Neurons
}

\author{
Alexander C. Jackson, Gui Lan Yao, and Bruce P. Bean \\ Department of Neurobiology, Harvard Medical School, Boston, Massachusetts 02115
}

We studied acutely dissociated neurons from the dorsomedial (shell) region of the rat suprachiasmatic nucleus (SCN) with the aim of determining the ionic conductances that underlie spontaneous firing. Most isolated neurons were spontaneously active, firing rhythmically at an average frequency of $8 \pm 4 \mathrm{~Hz}$. After application of TTX, oscillatory activity generally continued, but more slowly and at more depolarized voltages; these oscillations were usually blocked by $2 \mu \mathrm{m}$ nimodipine. To quantify the ionic currents underlying normal spontaneous activity, we voltage clamped cells using a segment of the spontaneous activity of each cell as voltage command and then used ionic substitution and selective blockers to isolate individual currents. TTX-sensitive sodium current flowed throughout the interspike interval, averaging $-3 \mathrm{pA}$ at $-60 \mathrm{mV}$ and $-11 \mathrm{pA}$ at $-55 \mathrm{mV}$. Calcium current during the interspike interval was, on average, fourfold smaller. Except immediately before spikes, calcium current was outweighed by calcium-activated potassium current, and in current clamp, nimodipine usually depolarized cells and slowed firing only slightly (average, $\sim 8 \%$ ). Thus, calcium current plays only a minor role in pacemaking of dissociated SCN neurons, although it can drive oscillatory activity with TTX present. During normal pacemaking, the early phase of spontaneous depolarization $(-85$ to $-60 \mathrm{mV})$ is attributable mainly to background conductance; cells have relatively depolarized resting potentials (with firing stopped by TTX and nimodipine) of -55 to $-50 \mathrm{mV}$, although input resistance is high (9.5 \pm $4.1 \mathrm{G} \Omega$ ). During the later phase of pacemaking (positive to $-60 \mathrm{mV}$ ), TTX-sensitive sodium current is dominant.

Key words: sodium current; calcium current; persistent sodium current; spike; pacemaking; pacemaker

\section{Introduction}

The suprachiasmatic nucleus (SCN) of the mammalian hypothalamus serves as the central biological clock, controlling circadian rhythms in physiology and behavior (for review, see Gillette and Tischkau, 1999; Reppert and Weaver, 2001). SCN neurons appear to fire action potentials spontaneously, with a circadian rhythmicity in the frequency of firing, higher during the daylight hours and lower at night (Inouye and Kawamura, 1979; Green and Gillette, 1982). Circadian regulation of electrical activity is present at the single-cell level, because dispersed SCN neurons continue to show a circadian rhythm in firing frequency (Welsh et al., 1995). Intensive recent work has identified a molecular clock based on feedback loops of transcription factors and enzymes, involving regulation of translation, dimerization, nuclear translocation, and degradation of multiple elements (King and Takahashi, 2000; Reppert and Weaver, 2001; Panda et al., 2002). However, how the molecular clock is linked to the regulation of electrical pacemaking of SCN neurons is still uncertain.

An understanding of the ionic currents that drive spontaneous firing of SCN neurons at any time of day is still incomplete. Although SCN neurons express the hyperpolarization-activated

Received June 2, 2004; revised July 28, 2004; accepted July 29, 2004.

This work was supported by National Institutes of Health Grants GM070774 and NS36855. We thank Drs. Nathaniel Blair, Michael Do, Michelino Puopolo, and Andrew Swensen for helpful discussion.

Correspondence should be addressed to Alexander C. Jackson, Department of Neurobiology, Harvard Medical School, 220 Longwood Avenue, Boston, MA 02115. E-mail: alexander_jackson@student.hms.harvard.edu. DOI:10.1523/JNEUROSCI.2146-04.2004

Copyright $\odot 2004$ Society for Neuroscience $\quad$ 0270-6474/04/247985-14\$15.00/0 cation current known as $I_{\mathrm{h}}$ (Akasu et al., 1993), blocking $I_{\mathrm{h}}$ has no effect on pacemaking (de Jeu and Pennartz, 1997; Pennartz et al., 1997). One candidate for inward current driving spontaneous depolarization of SCN neurons is a TTX-sensitive, voltagedependent sodium current that is activated at subthreshold voltages and inactivates slowly (Pennartz et al., 1997; Kononenko et al., 2004). Another is voltage-activated calcium current. Recently, Pennartz et al. (2002) reported that when treated with TTX, dorsomedial SCN (dmSCN) neurons studied during daytime continue to fire rhythmically in a $\mathrm{Ca}^{2+}$-dependent manner that is silenced by nimodipine, and they proposed that L-type $\mathrm{Ca}^{2+}$ current serves as a primary pacemaker current in SCN neurons. In addition, they showed that nimodipine-sensitive $\mathrm{Ca}^{2+}$ current is larger in daytime than nighttime, suggesting that its diurnal variation could be central to coupling the molecular clock to changes in firing rate.

Experiments to date have generally reported only modest effects of calcium channel blockers on firing of SCN neurons (Pennartz et al., 1997, 2002; Cloues and Sather, 2003). However, interpreting the effects of channel blockers on electrical pacemaking is difficult because block of any current alters the voltage trajectory and thus modifies activation of all other voltage-dependent currents. This problem is compounded in the case of calcium currents, which activate calcium-activated potassium currents, known to be present in SCN neurons (Cloues and Sather, 2003). If dissociated neurons that retain pacemaking activity can be obtained, a more direct examination of currents underlying pacemaking is possible using the action potential 
clamp technique (Llinás et al., 1982). By using the waveform of spontaneous firing as a voltage command in voltage-clamp mode, ionic substitution and pharmacological blockers can be used to quantify the contribution of individual components of current during spontaneous firing. We used this technique to examine the ionic conductances controlling spontaneous firing of SCN neurons.

\section{Materials and Methods}

SCN cell preparation. Acutely dissociated SCN neurons were isolated from the dorsomedial region of the SCN of the hypothalamus of LongEvans rats (age, postnatal days 12-16), using methods adapted from previous work (Huang, 1993; Taddese and Bean, 2002; Do and Bean, 2003). Rats were maintained on a $12 \mathrm{hr}$ light/dark cycle using normal fluorescent room light. Rats were anesthetized consistently and killed during the middle of the day, between 12:00 P.M. and 2:00 P.M. (lights on at 7:00 A.M.). Rats were anesthetized deeply with isoflurane and decapitated quickly into an ice-cold slurry of a HEPES-buffered highsucrose slicing solution composed of (in mM) $30 \mathrm{Na}_{2} \mathrm{SO}_{4}, 2 \mathrm{~K}_{2} \mathrm{SO}_{4}, 185$ sucrose, 10 glucose, $10 \mathrm{HEPES}, 0.5 \mathrm{CaCl}_{2}$, and $6 \mathrm{MgCl}_{2}, \mathrm{pH}$ 7.4. Blocks of brain containing the hypothalamus and intact optic nerves were blocked off and deposited into the sucrose slurry. The blocks were affixed immediately to the chilled platform of the slicing chamber, caudal side down, with cyanoacrylate glue. A vibrating tissue slicer (DTK-1000; DSK, Dosaka, Japan) was used to cut coronal hypothalamic slices $(300 \mu \mathrm{m}$ thick) using the optic chiasm as the primary landmark for identifying the region of the SCN. Hypothalamic slices caudal and rostral to the area of interest were also cut and later discarded. The slices were then transferred to the enzymatic dissociation solution, which consisted of $2.5 \mathrm{mg} / \mathrm{ml}$ protease XXIII (Sigma, St. Louis, MO) in sucrose solution and were incubated for $10 \mathrm{~min}$ at $34^{\circ} \mathrm{C}$. After enzyme treatment, the slices were rinsed in sucrose solution at room temperature and finally placed in cold $\left(4^{\circ} \mathrm{C}\right)$ sucrose solution containing $1 \mathrm{mg} / \mathrm{ml}$ trypsin inhibitor and $1 \mathrm{mg} / \mathrm{ml}$ bovine serum albumin.

The enzyme-treated slices were examined under a dissecting microscope, and those containing the SCN were retained while the others were discarded. Typically, only one or two $300 \mu \mathrm{m}$ slices containing the SCN could be obtained from a single brain. The SCN was identified as a bilaterally symmetrical, cell-dense region immediately superior to the optic chiasm and lateral to the inferior apex of the third ventricle (van den Pol, 1980). To isolate the dmSCN from enzyme-treated slices containing the central portion of the SCN, the white matter of the optic chiasm was separated from the gray matter and the approximate region of the dmSCN was cut out of the slice using iridectomy scissors under a dissecting microscope. Cutting the dorsomedial region of the SCN was based on preliminary experiments examining the pattern of staining for arginine-vasopressin (AVP), a marker for the dorsomedial "shell" region (Leak and Moore, 2001; Moore et al., 2002), in animals of the same age (see Fig. $1 \mathrm{~A}$ ). The chunks of dissected tissue were kept in sucrose solution at $4^{\circ} \mathrm{C}$ until use. Immediately before recording, single chunks were placed in a vial with a small volume of the storage sucrose solution and placed in an incubator at $34^{\circ} \mathrm{C}$ for $5 \mathrm{~min}$. The tissue chunk was then triturated gently through a fine-bore, fire-polished Pasteur pipette, generating a suspension of dissociated cells. A drop of the cell suspension was placed onto the glass-bottomed recording chamber and allowed to settle for $\sim 5$ min before rinsing away the sucrose solution and detritus by gentle flow of extracellular bath solution. In control experiments, the majority of dissociated neurons stained for AVP (see Fig. 1C) and are likely to correspond to "cluster I" neurons as defined by Pennartz et al. (1998a,b).

Electrophysiological recording. Current-clamp and voltage-clamp recordings were made using an Axopatch 200B amplifier (Axon Instruments, Union City, CA). Patch pipettes were pulled from borosilicate glass capillary tubes (VWR Scientific, West Chester, PA) and had resistances between 1.5 and $5 \mathrm{M} \Omega$ when filled with the standard intracellular solution. Electrodes were wrapped with Parafilm from the shank to near the tip to reduce pipette capacitance and permit optimal series resistance compensation. Current-clamp recordings were made in "fast" currentclamp mode to reduce distortion (Magistretti et al., 1996). The electrode wrapping was necessary to enable recording in this mode with low resistance electrodes without feedback oscillations in the amplifier.

Recording solutions and pharmacology. The standard internal solution was designed to approximate normal physiological conditions and consisted of (in mM) $123 \mathrm{~K}$-methanesulfonate, $9 \mathrm{NaCl}, 1.8 \mathrm{MgCl}_{2}, 0.9 \mathrm{EGTA}$, 9 HEPES, 14 Tris-creatine $\mathrm{PO}_{4}, 4 \mathrm{Mg}$-ATP, and 0.3 Tris-GTP, pH adjusted to 7.3 with $\mathrm{KOH}$. We have no knowledge of how much intracellular EGTA might best approximate physiological calcium buffering in SCN neurons; in early experiments, we tested lower levels $(0.09 \mathrm{~mm}$ EGTA) but found it more difficult to regularly make stable low-access resistance recordings. The standard external solution, which will be referred to as "1.2 Ca Tyrode's solution," consisted of (in mM) $150 \mathrm{NaCl}$, $3.5 \mathrm{KCl}, 1.2 \mathrm{CaCl}_{2}, 1 \mathrm{MgCl}_{2}, 10$ HEPES, and 10 glucose, $\mathrm{pH} 7.4$ with $\sim 5$ $\mathrm{NaOH}$ ). The concentrations of $\mathrm{CaCl}_{2}$ and $\mathrm{KCl}$ were chosen to mimic rat CSF more closely than the higher $\mathrm{CaCl}_{2}$ and lower $\mathrm{KCl}$ commonly used for electrophysiological recordings (Manthei et al., 1973; Jones and Keep, 1988; Brumberg et al., 2000). For “0 Ca Tyrode's," the $\mathrm{CaCl}_{2}$ was replaced by an equimolar amount of $\mathrm{MgCl}_{2}$ or $\mathrm{CoCl}_{2}$. To record calcium currents, $\mathrm{NaCl}$ was entirely replaced by equimolar TEA-Cl ("1.2 Ca-155 TEA solution." This solution consisted of (in mM) 150 TEA-Cl, $3.5 \mathrm{KCl}, 10$ HEPES, 10 glucose, $1 \mathrm{MgCl}_{2}$, and $1.2 \mathrm{CaCl}_{2}$, $\mathrm{pH} 7.4$ with $\sim 5$ TEA-OH. The " 0 Ca-155 TEA Tyrode's solution" was one in which the $\mathrm{CaCl}_{2}$ was replaced by an equimolar amount of $\mathrm{MgCl}_{2}$ or $\mathrm{CoCl}_{2}$, and the magnesium version was composed of (in $\mathrm{mM}$ ) $150 \mathrm{TEA}-\mathrm{Cl}, 3.5 \mathrm{KCl}, 10$ HEPES, 10 glucose, and $2.2 \mathrm{MgCl}_{2}$, pH 7.4 with TEA-OH. To explore the role of sodium ions in carrying background currents, we used a solution in which $N$-methyl-D-glucamine (NMDG) chloride replaced sodium chloride in Tyrode's solution (in mM: 150 NMDG, $3.5 \mathrm{KCl}, 10$ HEPES, 10 glucose, $1 \mathrm{MgCl}_{2}$, and $1.2 \mathrm{CaCl}_{2}, \mathrm{pH} 7.4$ with $\mathrm{HCl}$ ). This solution had a junction potential relative to Tyrode's solution of $+4 \mathrm{mV}$. Thus, when the cell was bathed in this solution (which was flowing from a flowpipe into bulk chamber solution of Tyrode's solution), nominal membrane potentials were corrected by $-4 \mathrm{mV}$ to calculate transmembrane voltage.

Solution changes were effected by moving cells in front of a horizontal array of 13 quartz flow pipes (inner diameter, $252 \mu \mathrm{m}$; outer diameter, $356 \mu \mathrm{m})$. All experiments were done at room temperature $\left(20-24^{\circ} \mathrm{C}\right)$.

Nimodipine was dissolved in the recording solution from a $10 \mathrm{~mm}$ stock in polyethylene glycol (PEG); in control experiments, application of diluted PEG alone had no effect on firing (firing rate in $0.04 \%$ PEG was $100 \pm 6 \%$ of that in control).

Acquisition and analysis. Data acquisition was performed using pCLAMP 8 (Axon Instruments), and data analysis was done using pCLAMP8 and IGORPro version 3.14. Cell capacitance was measured by subtracting capacitative transients recorded for a $10 \mathrm{mV}$ hyperpolarization from -78 to $-88 \mathrm{mV}$ just before and just after breaking through into the cell. When recording ionic currents, capacitative transients were reduced by using electronic capacitance compensation and, in some cases, performing additional digital correction after recording the data. As shown in Figures 7 and 8, most cells showed evidence of good voltageclamp control by the smooth and graded manner with which transient sodium currents were evoked by depolarizing voltage steps of increasing amplitude. In some cells, generally those with large sodium currents or with unusually long processes remaining after dissociation, sodium currents were less well controlled, and these were not used for analysis of transient sodium current. Some such cells were still used for analysis of interspike sodium currents because these currents were very small and slow.

Reported voltages have been corrected for a $-8 \mathrm{mV}$ junction potential between the potassium methanesulfonate-based internal solution and the Tyrode's solution present when zeroing pipette current, measured using a flowing $3 \mathrm{~m} \mathrm{KCl}$ bridge as described by Neher (1992).

The criterion for classifying a cell as showing oscillations in the presence of TTX was that the power spectral density function of membrane potential showed a well defined peak corresponding to a peak-to-peak amplitude of $\geq 3 \mathrm{mV}$ (Pennartz et al., 2002).

For a rhythmically firing cell with smooth spontaneous depolarization, it is impossible to rigorously define a spike threshold, and therefore the definition of "interspike interval" is somewhat arbitrary. We initially considered a definition of spike threshold as the voltage at which the 
absolute rate of change of voltage $(\mathrm{dV} / \mathrm{dt})$ reached $4 \mathrm{~V} / \mathrm{sec}$, a definition previously used for pacemaking cholinergic neurons (Bennett et al., 2000). This gave a value that varied considerably from cell to cell (mean, $-42.6 \mathrm{mV} ; \mathrm{SD}, \pm 9.8 \mathrm{mV} ; n=103)$. Using a definition as the voltage at which $\mathrm{dV} / \mathrm{dt}$ reached $4 \%$ of the maximum upstroke velocity gave similar, but somewhat less variable, values $(-44.9 \pm 4.8 \mathrm{mV} ; n=103)$, and in most cells corresponded reasonably well to an apparent inflection in the voltage trajectory. To compare membrane voltage before and after application of TTX, we calculated the average voltage with spikes removed. To do this, average voltage was calculated after excising a period corresponding to each spike, defined as extending from the spike threshold on the upstroke to the same voltage on the downstroke. As expected, for normal spontaneous firing, the voltage with spikes removed was slightly more negative $(-66.7 \pm 4.5 \mathrm{mV} ; n=103)$ than the average voltage including spikes $(-63.5 \pm 5.2 \mathrm{mV}, n=103)$. For oscillations in TTX, the voltage with spikes removed was $-52.3 \pm 5.8 \mathrm{mV}(n=103)$ compared with the average voltage including spikes of $-49.9 \pm 6.2 \mathrm{mV}(n=103)$.

\section{Results}

Isolation and identification of AVP neurons from the dmSCN We isolated neurons from the dorsomedial (shell) region of the SCN (dmSCN), focusing specifically on this region because it comprises a distinct anatomical and functional compartment within the SCN (Moore, 1983, 1996; van den Pol and Tsujimoto, 1985) that exhibits especially robust endogenous rhythmicity in clock gene expression (Hamada et al., 2001), c-fos gene expression (Jac et al., 2000), and electrical activity (Shibata et al., 1984; Derambure and Boulant, 1994). A large proportion of neurons in the dmSCN express the neuropeptide AVP (Moga and Moore, 1997). Therefore, to guide the dissection of this region for cell isolation, we first performed AVP immunocytochemistry on sections of the hypothalamus. Figure $1 A$ shows staining of a coronal hypothalamic slice using an anti-AVP primary antibody, followed by a biotinylated secondary antibody and the avidinbiotinylated peroxidase complex and diaminobenzidine substrate. The dorsomedial region of the SCN is evident by densely packed, AVP-positive neurons (Buijs et al., 1978). Neurons dissociated from this region (Fig. $1 B$ ) were relatively small, with oblong or pear-shaped cell bodies that were $7-15 \mu \mathrm{M}$ in the long axis and typically had one to four short processes remaining. A large proportion $(\sim 80-90 \%)$ of the dissociated neurons were stained by antibodies to AVP (Fig. 1C), suggesting that the dissection results in a reasonably homogenous population of neurons.

\section{Spontaneous firing in acutely dissociated $\mathrm{dmSCN}$ neurons}

Most neurons fired spontaneously in a regular and rhythmic manner, whether recorded in cell-attached mode before breaking through the membrane or in whole-cell current-clamp mode. Figure $2 \mathrm{~A}$ shows an example of spontaneous activity recorded in the cell-attached patch configuration. After breaking through the cell membrane into whole-cell mode, the neuron continued to fire at a similar rate (Fig. $2 \mathrm{~B}$ ), suggesting that the internal solution is effective in approximating physiological conditions. Occasionally, neurons were spontaneously active in the cell-attached patch configuration but were silent in whole-cell current-clamp mode; these could almost always be made to fire spontaneously by injection of a few picoamperes of steady hyperpolarizing current, suggesting that they were silenced by depolarization block, probably from leakage around the electrode seal. Such cells were not used for additional analysis.

The average spontaneous firing rate of dissociated $\mathrm{dmSCN}$ neurons recorded in whole-cell current-clamp mode was $8.2 \pm$ $3.8 \mathrm{~Hz}$ (mean $\pm \mathrm{SD} ; n=103$ ) and was generally highly regular,

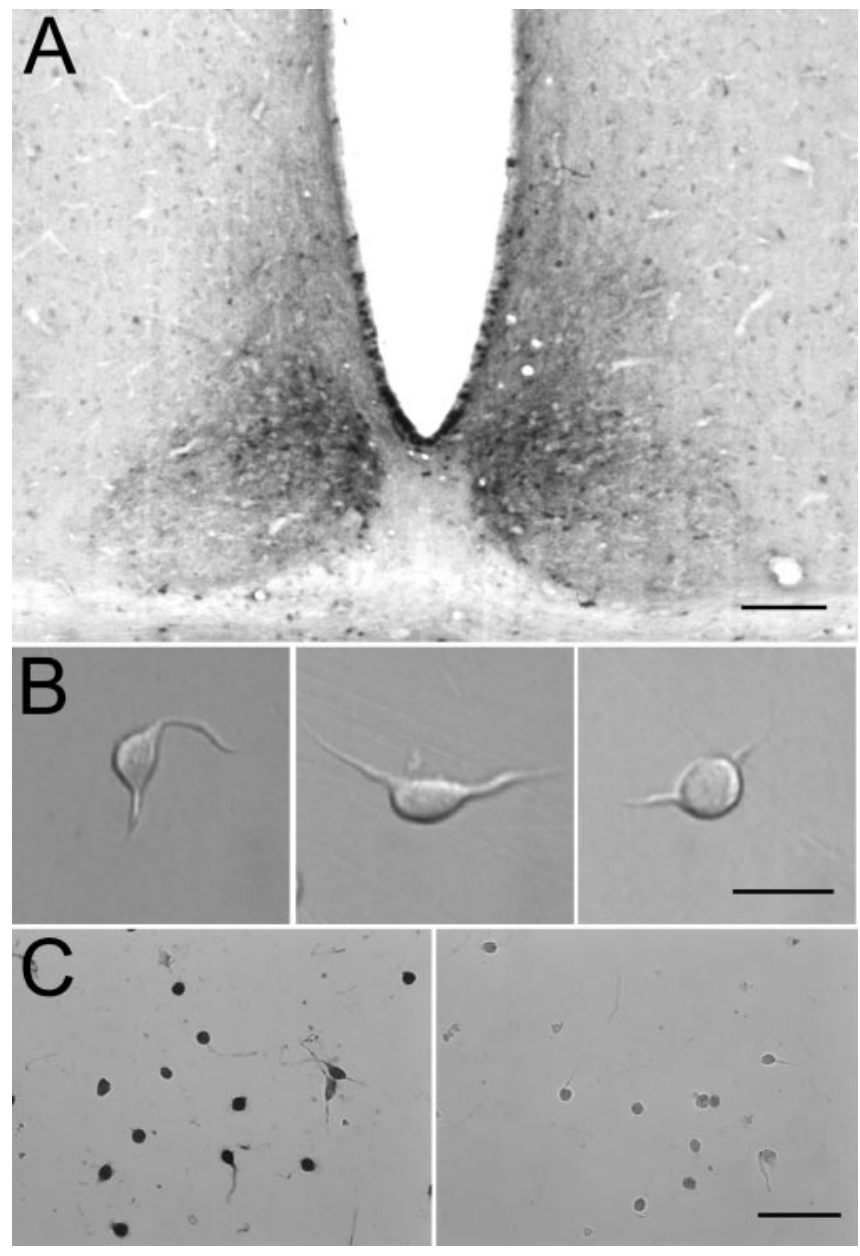

Figure 1. Dissociation of dmSCN neurons staining for AVP. A, Localization of dmSCN based on staining for AVP. Rabbit anti-AVP antibodies were used at a dilution of 1:1000, with a secondary antibody of biotinylated goat anti-rabbit lgG, followed by avidin-biotinylated peroxidase complex and diaminobenzidine substrate to form a reaction product. As a positive control, staining of both the paraventricular nucleus and supraoptic nucleus, both known to contain AVP-positive neurons, was also prominent. Scale bar, $100 \mu \mathrm{m}$. B, Morphology of freshly dissociated SCN neurons. Scale bar, $20 \mu \mathrm{m}$. C, Staining of dissociated SCN neurons with antiAVP antibodies. Left, Rabbit anti-AVP antibodies were used at a dilution of 1:1000, with a secondary antibody of biotinylated goat anti-rabbit lgG, followed by avidin-biotinylated peroxidase complex and diaminobenzidine substrate to form a reaction product. Right, Control using neurons treated identically but with nonimmunized rabbit lgG rather than anti-AVP. Scale bar, $50 \mu \mathrm{m}$. In another negative control, dissociated cortical neurons failed to be stained by the anti-AVP antibodies.

with an average coefficient of variation of the interspike interval of $16 \pm 10 \%$. Action potentials had peaks of $+26 \pm 10 \mathrm{mV}$, troughs of $-81 \pm 6 \mathrm{mV}$, and were relatively broad, with widths of $4.8 \pm 1.6 \mathrm{msec}$ (measured at the midpoint between peak and trough). The average maximum upstroke velocity was at $68 \pm 35$ $\mathrm{V} / \mathrm{sec}$.

The rhythmic spontaneous activity of acutely dissociated neurons confirms that the spontaneous firing of dmSCN neurons is attributable to intrinsic membrane properties of the cells and does not require ionotropic, metabotropic, or electrical synaptic transmission. The average firing of $8 \mathrm{~Hz}\left(\right.$ at $\left.22^{\circ} \mathrm{C}\right)$ is similar to rates seen for spontaneous firing of daytime $\mathrm{SCN}$ neurons studied in the brain slice (at $34-35^{\circ} \mathrm{C}$ ) when ongoing IPSPs are blocked (Pennartz et al., 2002; Kononenko and Dudek, 2004) and slightly faster than the average firing rate of $5-6 \mathrm{~Hz}$ seen in slices at room temperature (Cloues and Sather, 2003). The faster firing 
A cell-attached
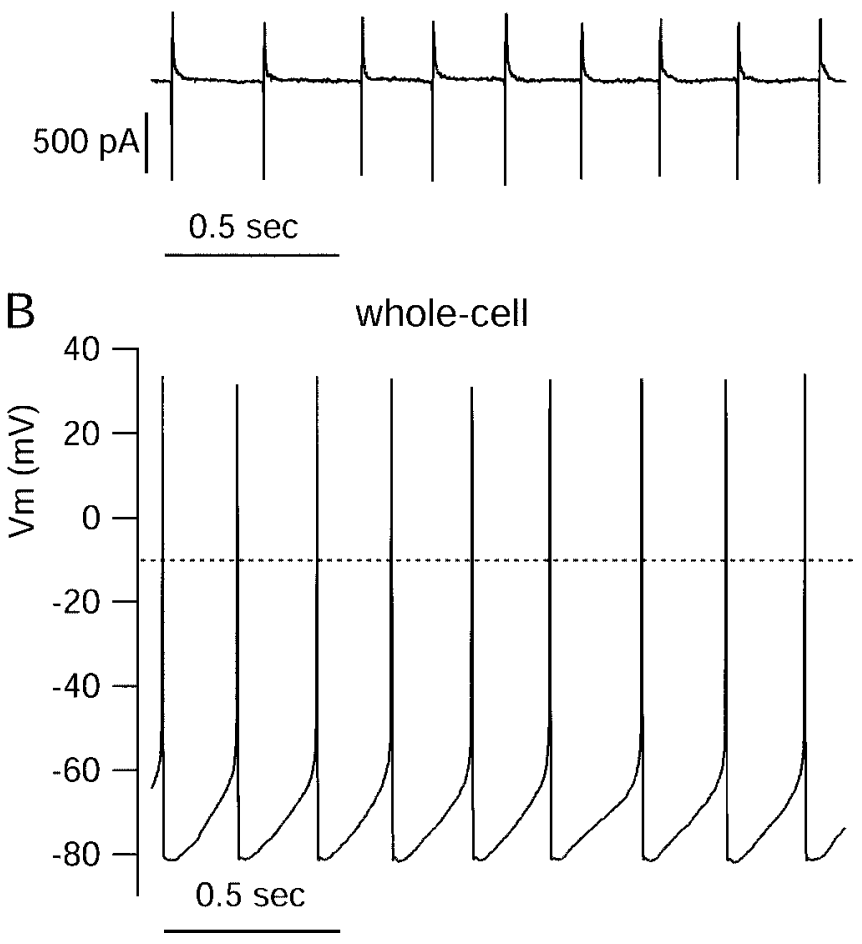

Figure 2. Spontaneous firing in a dissociated $S C N$ neuron recorded first in cell-attached patch mode and then in whole-cell current-clamp mode. $A$, Action currents from spontaneous firing recorded in cell-attached mode. $B$, Spontaneous firing recorded in whole-cell mode 7 min after breaking through into whole-cell mode. The pipette solutions consisted of (in $\mathrm{mM}$ ) 123 K-methanesulfonate, $9 \mathrm{NaCl}, 1.8 \mathrm{MgCl}_{2}, 0.9 \mathrm{EGTA}, 9$ HEPES, 14 creatine phosphate, $4 \mathrm{MgATP}$, and 0.3 GTP, pH7.3. The external solution included (in mM) $1.2 \mathrm{CaCl}_{2}, 3.5 \mathrm{KCl}, 150 \mathrm{NaCl}, 1 \mathrm{MgCl}_{2}$, 10 glucose, and 10 HEPES, pH 7.4.

of dissociated cells compared with cells in slice would be consistent with pacemaking originating in the soma and with a decreased capacitative load from dendrites when cells are dissociated. The highly regular firing seen with dissociated cells is consistent with experiments showing that the less regular firing typical of SCN cells in slice under physiological conditions is partly attributable to spontaneous synaptic potentials (Pennartz et al., 1998a), especially spontaneous IPSPs that stochastically lengthen interspike intervals (Konenenko and Dudek, 2004).

\section{Nimodipine-sensitive calcium oscillations in dissociated SCN neurons}

Figure 3 shows the effect of applying $300 \mathrm{nM}$ TTX to an SCN neuron firing rhythmically at $4.9 \mathrm{~Hz}$. Although fast spikes were eliminated by TTX, the membrane potential showed a continuing rhythmic oscillation, firing spikes with reduced amplitude (25-30 mV peak to trough) and at a lower frequency $(3.7 \mathrm{~Hz})$ than in control. The oscillatory activity in the presence of TTX was eliminated by the L-type calcium channel blocker nimodipine applied at $2 \mu \mathrm{M}$. The nimodipine-sensitive oscillatory behavior of dissociated neurons exposed to TTX is virtually identical to that of spontaneously active neurons in the $\mathrm{dmSCN}$ studied in brain slice (Pennartz et al., 2002). The majority (68 of 103) of spontaneously active acutely isolated neurons exhibited spontaneous oscillations when exposed to TTX. In five of eight cells tested, $2 \mu \mathrm{M}$ nimodipine silenced oscillations occurring in the presence of TTX, as in Figure 3. In two of the other three cells, the oscillations were reduced
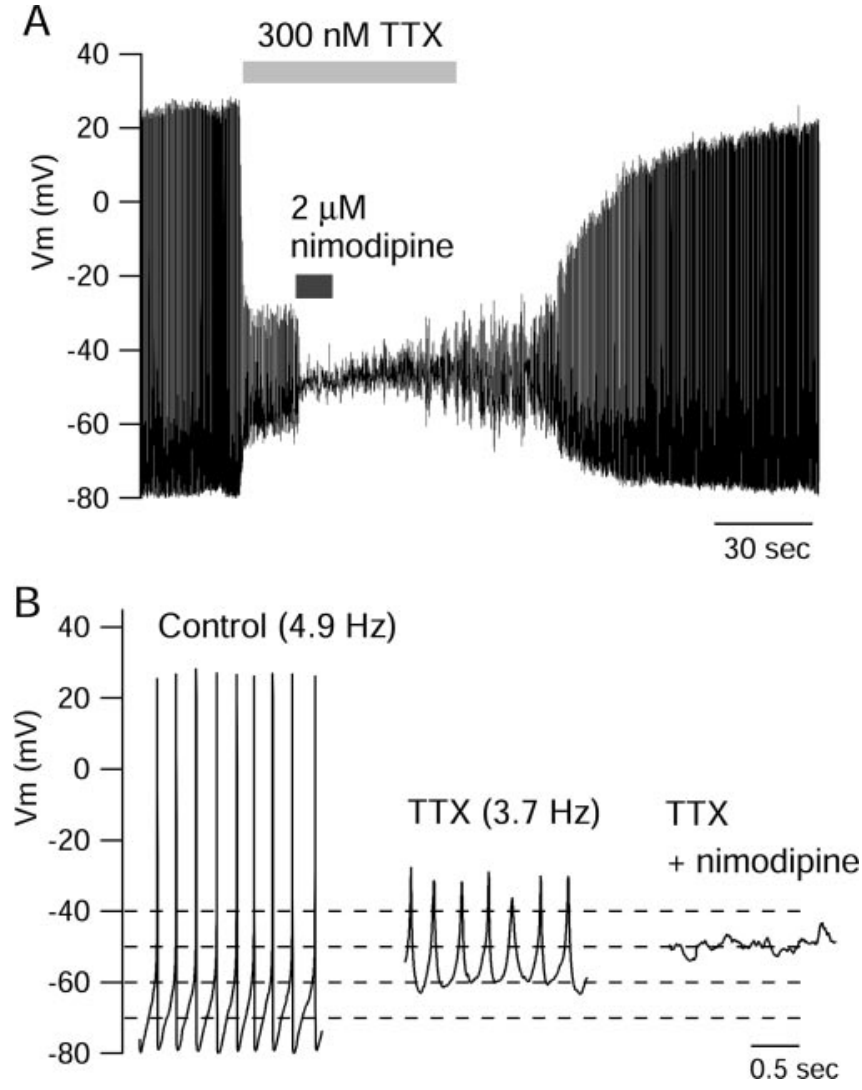

Figure 3. Oscillations of membrane potential in the presence of TTX. A, Effect of cumulative application of $300 \mathrm{~nm}$ TTX and $2 \mu \mathrm{m}$ nimodipine to an SCN neuron firing spontaneously at $4.9 \mathrm{~Hz}$. $B$, Two-second periods shown in each condition at an expanded time scale.

by nimodipine but not eliminated. The effect of nimodipine was fully reversible.

These results show that with sodium channels blocked, dissociated dmSCN neurons are capable of generating spontaneous oscillations driven by L-type calcium channels, just as in slice recordings (Pennartz et al., 2002). Does normal spontaneous firing in the absence of TTX result from underlying oscillations in membrane potential driven by L-type channels? In addressing this issue, it is notable that the nimodipine-sensitive oscillations in the presence of TTX differed from normal spontaneous firing in two ways. First, the frequency of the oscillations in TTX was always substantially lower than the frequency of normal spontaneous firing. In cells that exhibited rhythmic oscillations in the presence of TTX, the spontaneous firing rate in control was $7.9 \pm$ $3.7 \mathrm{~Hz}$, and the average frequency of oscillations in TTX was $3.9 \pm 2.3 \mathrm{~Hz}(n=68)$. Second, the voltage range over which the oscillations occurred in TTX was considerably depolarized relative to the voltage range during normal firing. In cells that oscillated in the presence of TTX, the average membrane potential during oscillations (with spikes removed) was $-52 \pm 6 \mathrm{mV}(n=$ 68) compared with an average membrane potential (with spikes removed) of $-67 \pm 5 \mathrm{mV}$ during normal spontaneous firing in the same cells before the addition of TTX.

\section{Action potential clamp analysis of currents flowing during and between spikes}

To determine the ionic currents that flow between spikes to produce the spontaneous depolarization that underlies normal spontaneous firing, we applied the action potential clamp tech- 

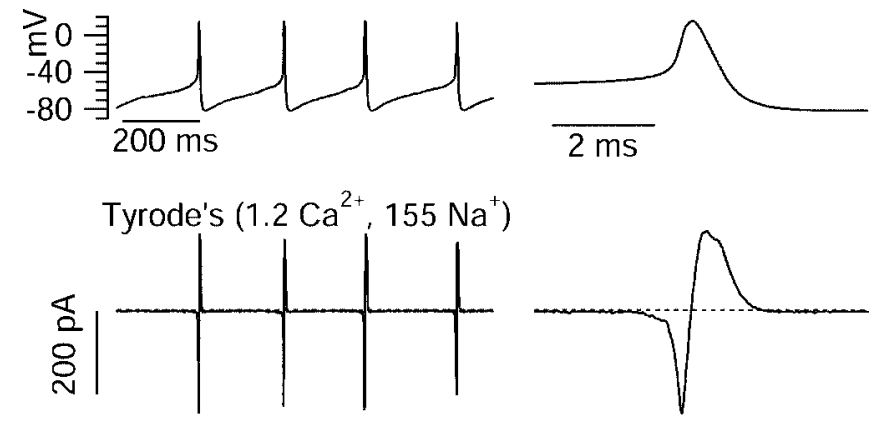

Tyrode's + 10 TEA $^{+}$

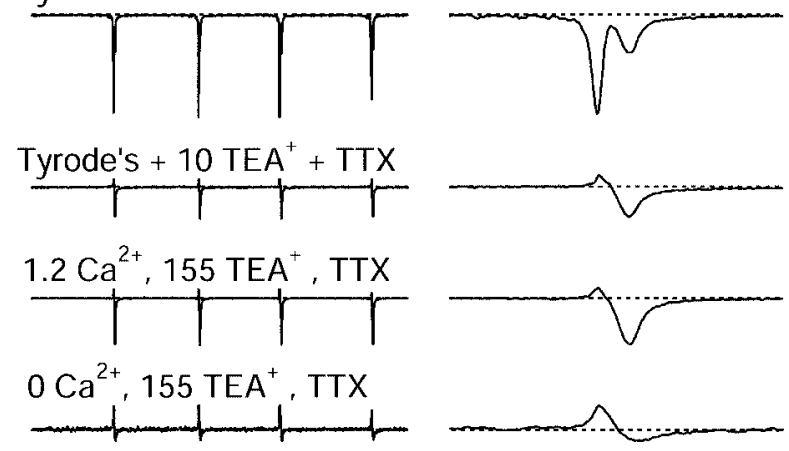

Figure 4. Action potential clamp technique using spontaneous action potentials. A period of spontaneous firing (no stimulation or steady injected current) was recorded in fast currentclamp mode (first row; left). The right column shows a single spike on an expanded time scale. Then the amplifier was switched to voltage-clamp mode, with compensation for whole-cell capacitance and series resistance; this tuning was done before the current-clamp recording, using a $10 \mathrm{mV}$ hyperpolarizing step from $-70 \mathrm{mV}$. The segment of spontaneous firing was used as voltage command. Second row, The ionic current elicited by this command (with capacitative current removed using electronic capacitance compensation in the patch clamp circuitry) in control Tyrode's solution. Third row, lonic current after moving cell to Tyrode's solution plus 10 mм TEA chloride. Fourth row, Current after moving cell to the same solution but with the addition of $300 \mathrm{~nm}$ TTX. Fifth row, Current after moving cell to solution in which $\mathrm{Na}^{+}$was replaced by $\mathrm{TEA}^{+}$. Sixth row, With cell in similar solution, except with $\mathrm{Ca}^{2+}$ replaced by $\mathrm{Mg}^{2+}$. The current remaining during the spike waveform in this solution is consistent with being capacitative transients attributable to incomplete compensation of whole-cell capacitance.

nique (Llinás et al., 1982; de Haas and Vogel, 1989) using the cycle of spontaneous firing of each cell as voltage command (Zaza et al., 1997; Taddese and Bean, 2002). We first recorded a $5 \mathrm{sec}$ segment of spontaneous firing in current-clamp mode (no stimulation or steady injected current) and then used the resulting waveform as the voltage command in voltage-clamp mode in the same cell. The principle behind this technique is that channels see the same voltage waveform whether in current clamp or voltage clamp, so that currents carried by purely voltage-dependent channels should be identical in both cases. In voltage-clamp, currents through individual types of ion channels can be separated using ionic substitution or specific blockers.

Because blocking $I_{\mathrm{h}}$ was previously found to have little or no effect on spontaneous firing (de Jeu and Pennartz, 1997; Pennartz et al., 1997), we focused on voltage-dependent sodium current and voltage-dependent calcium current as candidates for driving spontaneous firing. Figure 4 illustrates the sequence of solution changes used to isolate these currents. After recording spontaneous activity in current clamp, this waveform (Fig. 4, top) was used as the voltage command in voltage-clamp mode. The ionic current elicited by this command (with capacitative current removed using electronic capacitance compensation in the patch clamp circuitry) in control Tyrode's solution consisted of a large, fast inward current during the rising phase of each spike, followed by a somewhat longer-lasting outward current during the falling phase of the spike. When the cell was moved to Tyrode's solution containing $10 \mathrm{~mm}$ TEA chloride, the outward current was eliminated, showing that whatever combination of voltage-dependent and calcium-dependent potassium channels are present in SCN neurons, the major currents activated during the action potential are relatively sensitive to external TEA. The block of the outward current during the falling phase of the spike revealed a second phase of inward current flowing during the falling phase. The addition of $300 \mathrm{~nm}$ TTX blocked the inward current during the rising phase of the spike but had little effect on the inward current during the falling phase. The inward current during the falling phase became slightly larger when the TEA concentration was increased to $155 \mathrm{~mm}$ TEA, presumably because of block of a small component of opposing outward potassium current that was sensitive to $155 \mathrm{~mm}$ TEA but not $10 \mathrm{~mm}$ TEA. When the cell was moved to an external solution in which calcium was removed (replaced by equimolar magnesium), the inward current during the falling phase of the spike was mostly eliminated. The remaining small currents in this solution most likely represent incomplete compensation of capacitance.

With this sequence of solution changes, sodium current was isolated by subtraction of the currents before and after application of TTX, and calcium current was defined by subtraction of currents before and after replacement of calcium by magnesium in a background of $155 \mathrm{~mm}$ TEA to block potassium currents. In some experiments, calcium was replaced by cobalt, with no obvious difference in results compared with replacement by magnesium. Figure 5 shows the results of these subtractions for a cell in which currents were signal averaged over multiple cycles of spontaneous firing to improve the signal/noise ratio, thus allowing resolution of the small currents flowing between spikes as well as the larger currents flowing during spikes. As expected, sodium current (red trace) was largest during the upstroke of the action potential, in this cell reaching a peak of $\sim 950 \mathrm{pA}$. Strikingly, however, TTX-sensitive sodium current was also present throughout the interspike interval (Fig. 5C). During the first half of the interspike interval, as the cell depolarized gradually from -85 to $-70 \mathrm{mV}$ over $\sim 50 \mathrm{msec}$, inward sodium current was relatively steady near $-1.5 \mathrm{pA}$. It increased gradually to $\sim-2.5$ $\mathrm{pA}$ as the voltage depolarized to $-65 \mathrm{mV}$ and then more quickly, reaching $-5 \mathrm{pA}$ at $-60 \mathrm{mV}$ and then $-15 \mathrm{pA}$ at $-55 \mathrm{mV}$, after which it increased very steeply during the upstroke of the action potential.

Calcium current (blue traces) showed a small surge $(\sim 17 \mathrm{pA})$ during the rising phase of the action potential, followed by a much larger peak during the falling phase $(\sim 100 \mathrm{pA})$. However, in contrast to sodium current, calcium current was near zero throughout the initial two-thirds of the spontaneous interspike depolarization and exceeded $1 \mathrm{pA}$ only positive to $-60 \mathrm{mV}$. Calcium current was far smaller than sodium current throughout the interspike depolarization.

The results for the cell shown in Figure 5 were typical, with clear TTX sodium current flowing throughout the interspike interval and much smaller calcium currents until after the spike. Figure 6 shows collected results from 13 cells studied with this protocol. Results from different cells (each with a somewhat different firing rate and interspike voltage trajectory) were averaged by converting traces of current versus time to current versus voltage during the interspike depolarization (Fig. 6A). In collected results from 13 cells, TTX-sensitive sodium current was $-0.77 \pm$ $0.37 \mathrm{pA}$ at $-70 \mathrm{mV},-3.2 \pm 2.6 \mathrm{pA}$ at $-60 \mathrm{mV},-11 \pm 13 \mathrm{pA}$ at $-55 \mathrm{mV}$, and $-47 \pm 94 \mathrm{pA}$ at $-50 \mathrm{mV}$ compared with calcium 

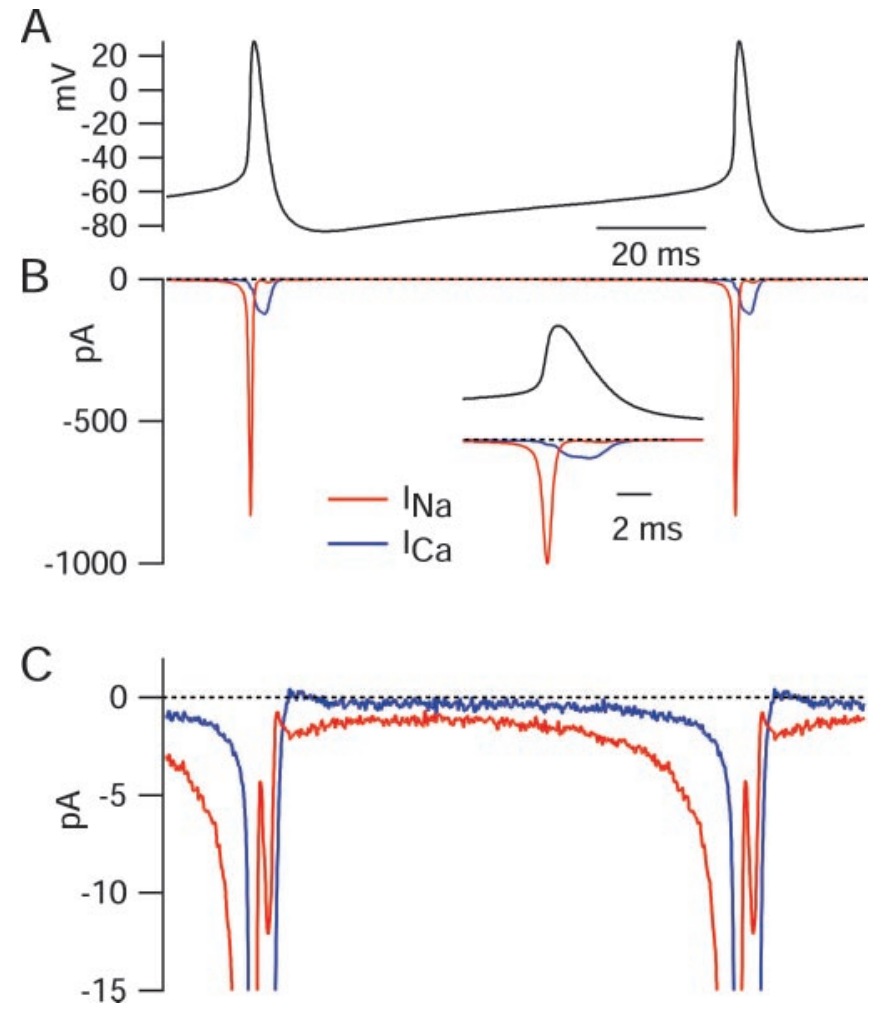

Figure 5. Interspike sodium and calcium currents determined using the action potential clamp technique. $A$, Voltage during the cycle of spontaneous firing was signal averaged by aligning action potentials from a 5 sec period of recording at their peaks and signal averaging. $A$ unit cycle of firing resulting from this procedure was concatenated so as to illustrate slightly more than one complete cycle. $B$, Sodium current (red) in response to the 5 sec action potential waveform was calculated by subtraction of currents before and TTX as in Figure 4. Current was signal averaged in an identical manner as the voltage in $A$ (using the times of the action potential peaks to perform the alignment). Calcium current (blue) was signal averaged in an identical manner based on the subtraction of currents recorded with and without $\mathrm{Ca}^{2+}$ (replaced by $\mathrm{Mg}^{2+}$ ), both in the presence of $155 \mathrm{~mm} \mathrm{TEA}{ }^{+}$to block calcium-activated potassium currents. Inset, Sodium and calcium currents during the spike, shown on an expanded time base. C, Same currents as in $B$ shown on an expanded current scale to resolve currents during the interspike interval.

current of $-0.23 \pm 0.23 \mathrm{pA}$ at $-70 \mathrm{mV},-0.75 \pm 0.49 \mathrm{pA}$ at -60 $\mathrm{mV},-1.6 \pm 1.1 \mathrm{pA}$ at $-50 \mathrm{mV}$, and $-2.9 \pm 1.6 \mathrm{pA}$ at $-50 \mathrm{mV}$. Thus, calcium current was, on average, far smaller than TTXsensitive sodium current throughout the interspike interval.

To quantify the relative contribution of sodium and calcium current in driving the spontaneous interspike depolarization in another way, we integrated each of these currents during the interspike interval, defining the interspike interval as beginning at the trough after a spike (on average, $-82 \pm 6 \mathrm{mV} ; n=13$ ) and extending to near spike threshold. The definition of spike threshold is arbitrary for a spontaneously firing cell. We defined threshold as the voltage at which the rate of change of voltage reached $4 \%$ of the maximum upstroke, which corresponded visually to an apparent inflection in the voltage trajectory, after which the rate of depolarization became very rapid. Defined in this way, threshold averaged $-45 \pm 5 \mathrm{mV}(n=103)$. Taking account of the variable threshold from cell to cell, we defined the interspike interval as the time from the trough after a spike to the time at which the voltage reached $-55 \mathrm{mV}$, chosen to be somewhat negative to the average spike threshold. Integrated sodium current over this interval was always larger than integrated calcium current, usually by many-fold, and this was true in cells that fired
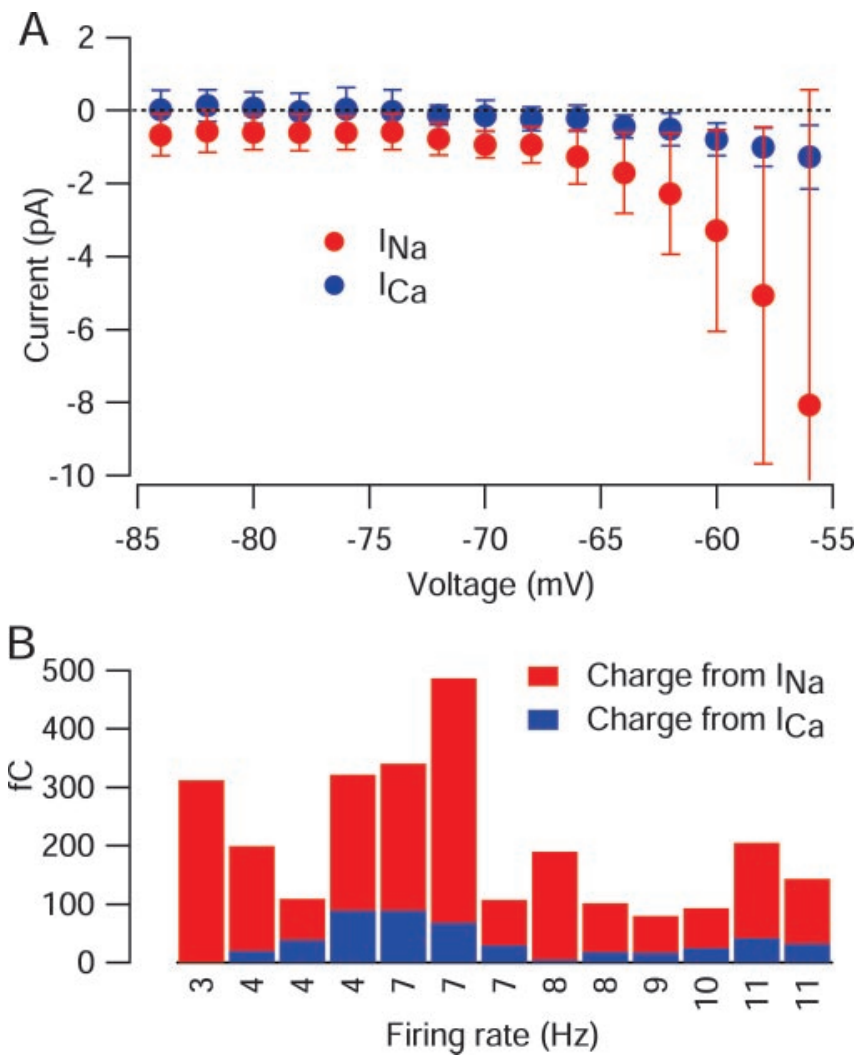

Figure 6. Comparison of current from calcium channels and TTX-sensitive sodium channels during the interspike interval of 13 SCN neurons. In each cell, sodium and calcium currents flowing during the cycle of spontaneous firing were determined as in Figure 5. To allow comparisons among cells, current as a function of time was converted to current as a function of interspike voltage for each cell. $A$, Sodium (red) and calcium (blue) currents during the interspike interval, averaged over 13 cells. The error bars show SD. $B$, Cell-by-cell comparison of sodium and calcium currents integrated from the trough after a spike to the time at which the voltage reached $-55 \mathrm{mV}$. Cells are arranged by their firing rate; there was no systematic dependence of relative contribution of sodium versus calcium current on firing rate.

relatively slowly as well as those that fired relatively quickly (Fig. $6 B)$. In 13 cells, integrated interspike sodium current amounted to $170 \pm 109 \mathrm{fC}$, and integrated interspike calcium current was $36 \pm 29 \mathrm{fC}$. When compared cell by cell, integrated interspike calcium current amounted to $26 \pm 16 \%$ of the integrated interspike TTX-sensitive sodium current.

The charge carried by sodium channels and calcium channels can be compared with the total charge necessary to depolarize the cells from the trough to $-55 \mathrm{mV}$, equal to cell capacitance times the change in voltage. In these 13 cells, cell capacitance was $5.7 \pm$ $1.7 \mathrm{pF}$, integrated interspike TTX-sensitive sodium current amounted to $114 \pm 58 \%$, and integrated calcium current to $27 \pm$ $20 \%$ of the net inward charge movement corresponding to the spontaneous depolarization from trough to $-55 \mathrm{mV}$. As will be discussed, there are other sources of inward charge movement in addition to calcium current and TTX-sensitive sodium current, and also partially counterbalancing potassium currents. Thus, the contribution of calcium current to the total inward charge movement driving spontaneous depolarization is probably well below $25 \%$.

This analysis suggests that flow of calcium current plays a relatively minor role in driving pacemaking of $\mathrm{dmSCN}$ neurons. If there were an important role for calcium current in a particular subset of cells, these would likely be the cells showing the ability to produce calcium-dependent oscillations in the presence of TTX. 
A

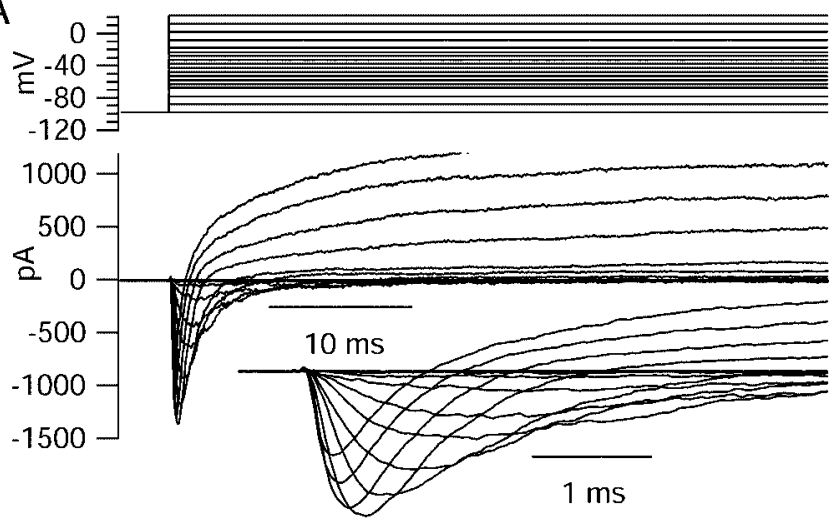

B Steady-state current

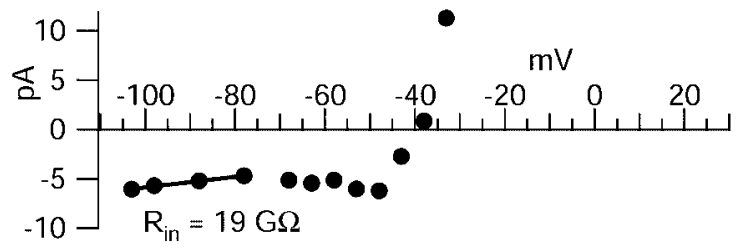

C Peak current

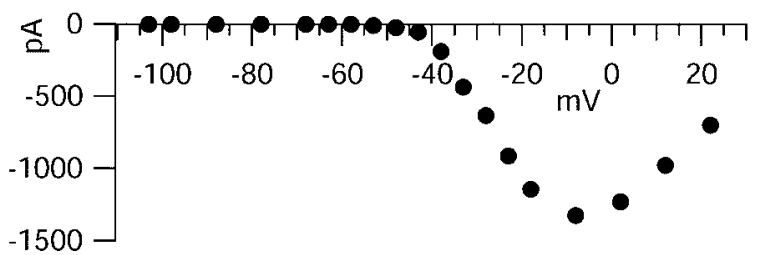

Figure 7. Voltage-activated ionic current elicited by step depolarizations. $A$, Total ionic current evoked by voltage steps from a holding potential of $-78 \mathrm{mV}$ studied with physiological solutions. There was no correction for leak or background current. Capacity transients were electronically nulled using the amplifier circuitry, and remaining transients were corrected digitally by scaling and subtracting the capacity transient for a $10 \mathrm{mV}$ hyperpolarization. B, Steadystate current measured at the end of 200 msec steps. Note low steady-state background conductance, inward inflection between -70 and -50 , corresponding to persistent sodium current, and steep activation of apparent voltage-dependent potassium current positive to $-50 \mathrm{mV}$. The solid line shows linear fit to the current-voltage relationship between -100 and $-75 \mathrm{mV}$. C, Peak inward transient current during test step.

We therefore analyzed interspike sodium and calcium currents in a subset of cells in which it was possible to also apply TTX in current clamp and to verify their ability to generate rhythmic oscillatory activity under this condition. This was true of 9 of the 13 cells for which we analyzed interspike currents using the voltage-clamp method. In these nine cells, integrated interspike calcium current measured during normal pacemaking amounted to $34 \pm 23 \mathrm{fC}$, amounting to $27 \pm 17 \%$ of the net charge necessary for depolarization from the trough to $-55 \mathrm{mV}$, similar to the population as a whole and much smaller than the interspike sodium current in the same cells (contributing $117 \pm 60 \mathrm{fC}, 90 \pm$ $43 \%$ of the net charge).

\section{Voltage dependence of sodium and calcium currents elicited by step depolarizations}

To gain additional insight into the nature of the ionic currents flowing between spontaneous action potentials, we characterized the voltage dependence and kinetics of sodium and calcium currents using step depolarizations. Figure $7 A$ shows total ionic current flowing in response to a series of voltage steps from a holding potential of $-78 \mathrm{mV}$ studied with solutions approximating physiological conditions (the same used for current-clamp recordings), with an external solution containing $155 \mathrm{mM} \mathrm{Na}^{+}$and 1.2 $\mathrm{mM} \mathrm{Ca}{ }^{2+}$. Capacity transients were electronically nulled using the compensation circuitry on the amplifier (and remaining transients were corrected for digitally), and series resistance compensation was used, but the currents are otherwise shown in raw form, with no correction or compensation for "leak" or background current. One striking result was the low background conductance (high input resistance) of the neurons. For the currents shown in Figure 7, the current-voltage relationship for steadystate current (measured at the end of the $200 \mathrm{msec}$ steps) was linear in the range from -100 to $-75 \mathrm{mV}$ (Fig. $7 B$ ), with a slope corresponding to an input resistance of $19 \mathrm{G} \Omega$. Between -70 and $-50 \mathrm{mV}$, the steady-state current-voltage relationship showed a region of "negative conductance" in which current became more inward with increasing depolarization. This likely corresponds to steady-state activation of "persistent" sodium current in this voltage range (Crill, 1996; Taddese and Bean, 2002). Steady-state current reversed at $-40 \mathrm{mV}$.

Depolarizations positive to $-50 \mathrm{mV}$ activated transient inward currents (Fig. 7A) that were evoked in a smooth and graded manner by depolarizing voltage steps of increasing amplitude, consistent with accurate voltage control. These currents reached a peak near $-10 \mathrm{mV}$ (Fig. $7 C$ ) and were primarily ( $\sim 95 \%)$ TTXsensitive sodium currents, with a small contribution from calcium currents. Sodium currents and calcium currents evoked by step depolarizations were isolated using the same sequence of solution changes as for action potential-elicited currents (Fig. 8). The voltage dependence of sodium channel activation, expressed as peak conductance versus voltage, could be fit well by a Boltzmann function (Fig. 8C). Calcium currents, obtained by subtraction of currents before and after replacing calcium by cobalt (Fig. $8 D$ ) in the presence of $155 \mathrm{~mm}$ TEA to block potassium currents, appeared to have little or no contribution from T-type channels, judged by their fast $(<1 \mathrm{msec})$ tail currents and slow inactivation of currents at -50 or $-40 \mathrm{mV}$. There was never obvious T-type current elicited from a holding potential of $-78 \mathrm{mV}$. However, in a series of experiments done with a holding potential of $-98 \mathrm{mV}$, a few cells did show small T-type currents.

Step-evoked calcium current was always far less than sodium current at all voltages, as in Figure 8. In collected results, peak transient sodium current was $2.0 \pm 1.0 \mathrm{nA}(n=37)$, usually reaching a peak between -20 and $-10 \mathrm{mV}$, and calcium current was $120 \pm 41 \mathrm{pA}(n=12)$, reaching a peak near $-10 \mathrm{mV}$. When expressed as conductance, the calcium currents activated with a shallower slope, more depolarized midpoint, and much smaller maximal conductance than sodium currents (Fig. $8 E$ ). Thus, the step-activated sodium conductance was always much larger than step-activated calcium conductance at all voltages, just as for the interspike currents carried through these channels.

\section{Voltage dependence of nimodipine-sensitive calcium current} Recordings from dmSCN neurons in brain slice have suggested a special role for calcium channels sensitive to the L-type calcium channel blocker nimodipine (Pennartz et al., 2002), although these underlie only $20-40 \%$ of the total voltage-activated calcium current (Pennartz et al., 2002; Cloues and Sather, 2003). We therefore examined the voltage dependence and kinetics of the nimodipine-sensitive component of calcium current (Fig. 9). On average, nimodipine inhibited peak calcium current by $29 \pm 11 \%$ $(n=6)$, very similar to the previous observations in slice record- 
A

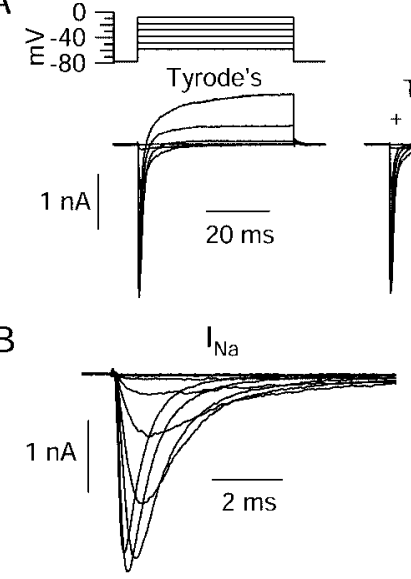

D
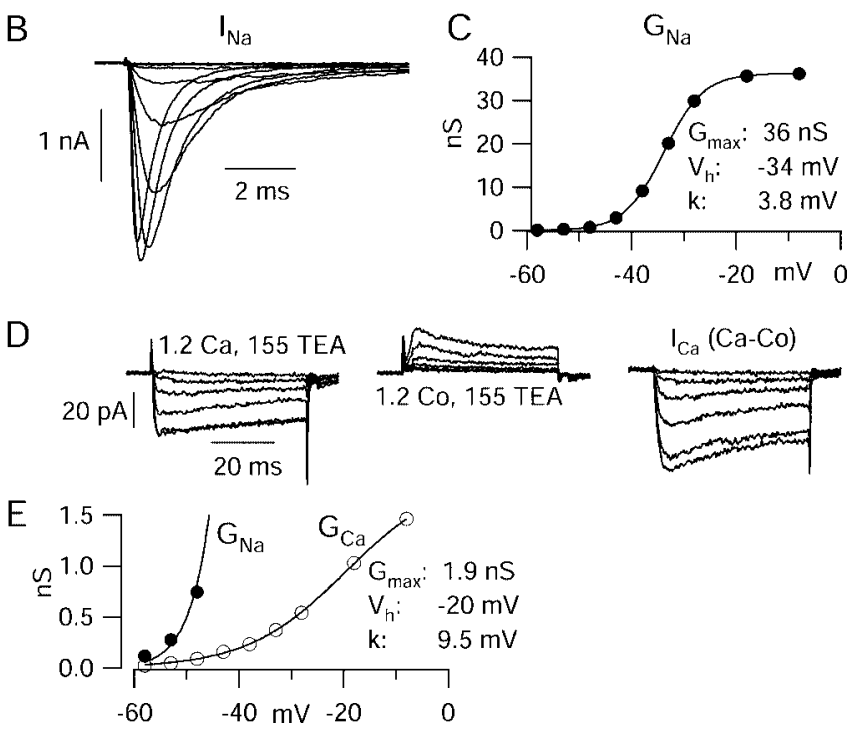

Figure 8. Isolation of voltage-activated sodium and calcium currents elicited by step depolarizations. A, lonic currents evoked in response to depolarizing pulses in control (left), with 10 mM TEA present in the external solution (middle), and with both TEA and $300 \mathrm{~nm}$ TTX present (right). $B$, TTX-sensitive sodium current obtained by subtraction of currents before and after TTX. C, Voltage dependence of peak transient sodium conductance, obtained by converting TTX-sensitive sodium current to a conductance (using the measured reversal potential of +45 $\mathrm{mV})$. The solid line is plotted according to $G_{\mathrm{Na}}=G_{\max } /\left[1+\exp \left(-\left(V-V_{\mathrm{h}}\right) / k\right)\right]$, where $G_{\max }$ is the maximal conductance $(36 \mathrm{nS}), V$ is the test potential, $V_{\mathrm{h}}$ is the midpoint $(-34 \mathrm{mV})$, and $k$ is the slope factor $(3.8 \mathrm{mV})$. D, lonic currents evoked by a series of solutions enabling isolation of calcium current: a solution in which external sodium in Tyrode's solution was replaced by TEA (left) and the same solution but with cobalt replacing calcium (middle). Subtraction of currents in these solutions yields calcium current (right). E, Open symbols indicate depolarizationevoked calcium conductance, calculated by converting calcium current to conductance using a reversal potential of $+57 \mathrm{mV}$. The solid curve is plotted according to $G_{\mathrm{Ca}}=1.9 \mathrm{nS} /[1+$ $\exp (-(V+20) / 9.5)]$; the closed symbols and fit: $G_{\mathrm{Na}}$ (from $C$ plotted on same scale to illustrate relative size of voltage-activated calcium and sodium conductances.

ings made by Pennartz et al. (2002) and Cloues and Sather (2003), who reported inhibition by 38 and $20 \%$, respectively.

The nimodipine-sensitive component of calcium current activated at relatively negative voltages compared with overall calcium current (Fig. 9B). When fit by Boltzmann curves, the nimodipine-sensitive component had a midpoint of $-30 \pm 6 \mathrm{mV}$ $(n=6)$ and a slope factor of $7.9 \pm 2.3 \mathrm{mV}$, whereas total current had a midpoint of $-18 \pm 6 \mathrm{mV}(n=6)$ and a slope factor of $8.9 \pm$ $2.1 \mathrm{mV}$. In these six cells, total calcium current was $-108 \pm 13$ $\mathrm{pA}$, and nimodipine-sensitive current was $-30 \pm 8 \mathrm{pA}$, measured for steps to $-8 \mathrm{mV}$. Thus, although nimodipine-sensitive current forms a modest fraction of total calcium current, it is activated by smaller depolarizations than the other types of calcium currents present in the neurons. Consistent with this, experiments using the action potential clamp showed that the calcium current activated during the spontaneous depolarization leading up to a spike is primarily from nimodipine-sensitive channels (Fig. 10). TTX-sensitive sodium current was also re-
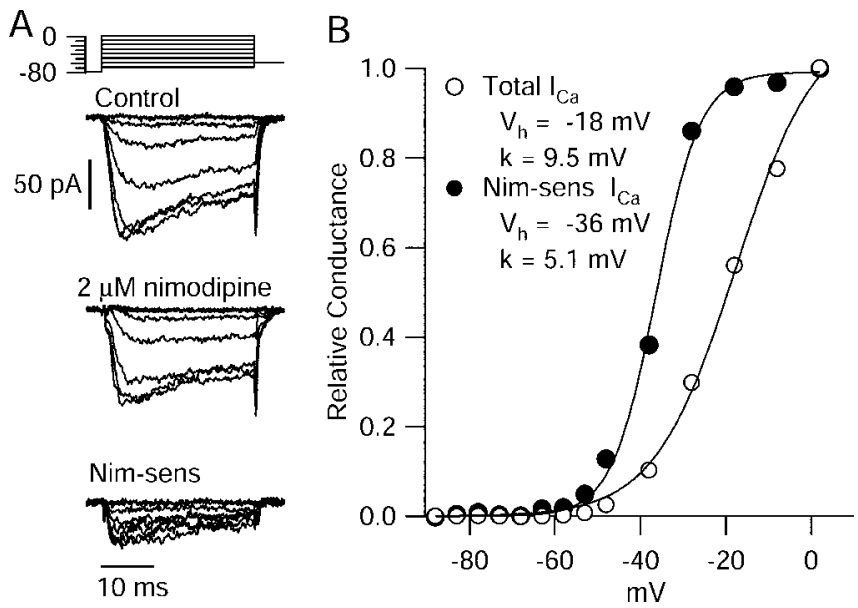

Figure 9. Voltage dependence of nimodipine-sensitive calcium current. $A$, Top, Total calcium current with physiological calcium $(1.2 \mathrm{~mm})$ as charge carrier, obtained by subtraction of currents after replacing calcium with cobalt (with sodium replaced with $155 \mathrm{~mm}$ TEA to block potassium currents) as in Figure 8 . Middle, Same, but with both calcium- and cobalt-containing solutions containing $2 \mu \mathrm{m}$ nimodipine. Bottom, Nimodipine-sensitive calcium current. $B$, Normalized total calcium conductance (open symbols) and nimodipine-sensitive calcium conductance (closed symbols) as a function of voltage. Conductance was calculated from peak current using a reversal potential of $+57 \mathrm{mV}$. The solid lines indicate Boltzmann functions plotted according to $G_{\max } /\left[1+\exp \left(-\left(V-V_{h}\right) / k\right)\right]$, where $G_{\max }$ is the maximal conductance, $V$ is the test potential, $V_{\mathrm{h}}$ is the midpoint, and $k$ is the slope factor, with the indicated values.

corded in the cell shown in Figure 10 and was much larger than calcium current at all voltages during the phase of spontaneous depolarization.

\section{The effect of nimodipine on characteristics of spontaneous firing}

We next examined the effect of nimodipine on the spontaneous firing of dissociated dmSCN neurons. Current-clamp recordings from $\mathrm{dmSCN}$ neurons in slices have shown a modest slowing of spontaneous firing with nimodipine application, with average slowing by $\sim 30 \%$ when studied at $32^{\circ} \mathrm{C}$ with perforated-patch recording (Pennartz et al., 2002) and by $\sim 20 \%$ in ruptured-patch whole-cell configuration (Cloues and Sather, 2003). The effect of $2 \mu \mathrm{M}$ nimodipine on spontaneously firing dissociated SCN neurons varied from cell to cell and was generally small. On average, nimodipine changed firing frequency by an average of $-8 \pm 19 \%$ $(n=15)$, from initial rates averaging $8.8 \pm 3.5 \mathrm{~Hz}$. The large SD reflects qualitatively different results in different cells: of the 15 cells tested, nimodipine slowed firing in 8 , speeded firing in 5 , and produced no change in 2 . Figure 11 shows an example in which 2 $\mu \mathrm{M}$ nimodipine reversibly slowed the firing rate, in this case producing a $19 \%$ slowing, from 4.3 to $3.5 \mathrm{~Hz}$. The effects of nimodipine were not any more dramatic in a subset of eight cells that were verified to be able to generate calcium-dependent oscillations in the presence of TTX; in these cells, nimodipine changed the firing frequency by an average of $-8 \pm 18 \%$, similar to the overall population. Thus, there is no indication that nimodipinesensitive currents are any more crucial for spontaneous firing of these neurons than for the general population.

If nimodipine acted simply by inhibiting an inward calcium current, it would slow firing by introducing a net hyperpolarizing influence. In fact, however, nimodipine produced a net depolarizing effect in most cells ( 9 of 15), as in Figure 11, and had no net effect $(<1 \mathrm{mV})$ in the other 6 cells. The average trough of the hyperpolarization after spikes was depolarized by an average of $+3.5 \pm 3.2 \mathrm{mV}$, and the average membrane voltage (integrated 
A
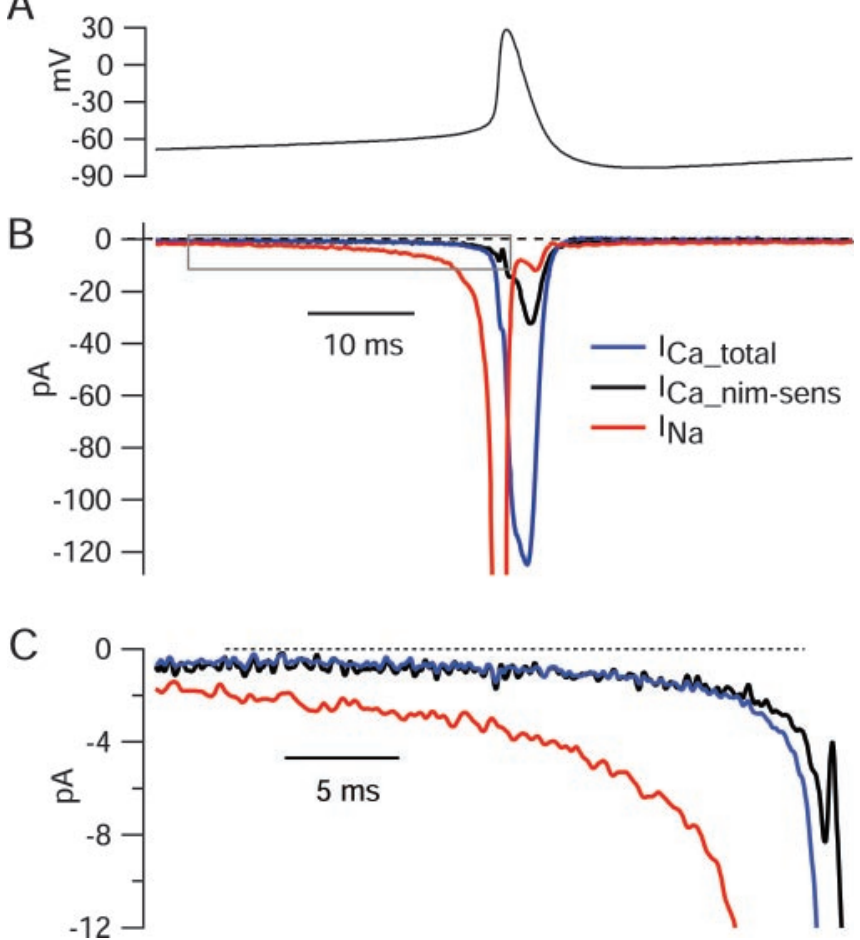

Figure 10. Preferential activation of nimodipine-sensitive calcium current before spontaneous action potentials. A 5 sec segment of spontaneous activity was recorded in current clamp and used as command waveform in voltage clamp. $A$, Voltage trajectory before and during the spike, signal averaged over 48 spikes (aligned at spike peaks). B, Sodium current (red) was determined as the current sensitive to $300 \mathrm{~nm}$ TTX. Total calcium current (blue) was determined by recording current in a solution containing (in mM) $1.2 \mathrm{CaCl}_{2}, 1 \mathrm{MgCl}, 150$ TEA-Cl, $3.5 \mathrm{KCl}, 10$ HEPES, and 10 glucose, pH to 7.4 with TEAOH, and subtracting current recorded in a solution that was identical, except with $\mathrm{CoCl}_{2}$ replacing $\mathrm{CaCl}_{2}$. Nimodipine-sensitive calcium current (black) was recorded as the current sensitive to $2 \mu \mathrm{m}$ nimodipine applied in the solution containing (in mM) $1.2 \mathrm{CaCl}_{2}, 1 \mathrm{MgCl}_{2}$, and $150 \mathrm{TEA}-\mathrm{Cl}$. Current in each solution was signal averaged over 96-192 cycles of firing. C, Currents before spike shown on an expanded current and time scale (box in $B$ ).

over the entire cycle of firing) was depolarized by an average of $+2.8 \pm 2.7 \mathrm{mV}$, although the peak of the action potentials was reduced (by an average of $-4.9 \pm 5.5 \mathrm{mV}$ ). In the few cells in which nimodipine produced an increase in firing rate, this was also accompanied by a net depolarization. In fact, the depolarization was particularly large in these cells; in the three cells in which nimodipine speeded firing by $>10 \%$ (by an average, of $13 \pm 3 \%$ ), the afterhyperpolarization depolarized by $+6.6 \pm 2.9 \mathrm{mV}$, and the averaged membrane potential depolarized by $+5.9 \pm 0.1 \mathrm{mV}$.

It seems most likely that the depolarizing effect of nimodipine is caused by inhibition of calcium-activated potassium current, secondary to inhibition of calcium entry through L-type calcium channels. It seemed possible that the modest slowing effect of nimodipine could be secondary to the net depolarization produced by the drug: depolarization could slow firing by producing net inactivation of voltage-dependent sodium channels so that less inward current flows near threshold voltages. The reduction in the overshoot of the action potential is consistent with such inactivation, and the maximum rate of rise of spikes also generally decreased with nimodipine (changing by an average of $-22 \pm 20 \%)$. To determine whether the slowing effects of nimodipine were secondary to depolarization, we tested whether producing an equivalent small depolarization by injection of a small depolarizing current would produce a similar slowing in firing rate. It did not. In all cases in which depolarizing current was
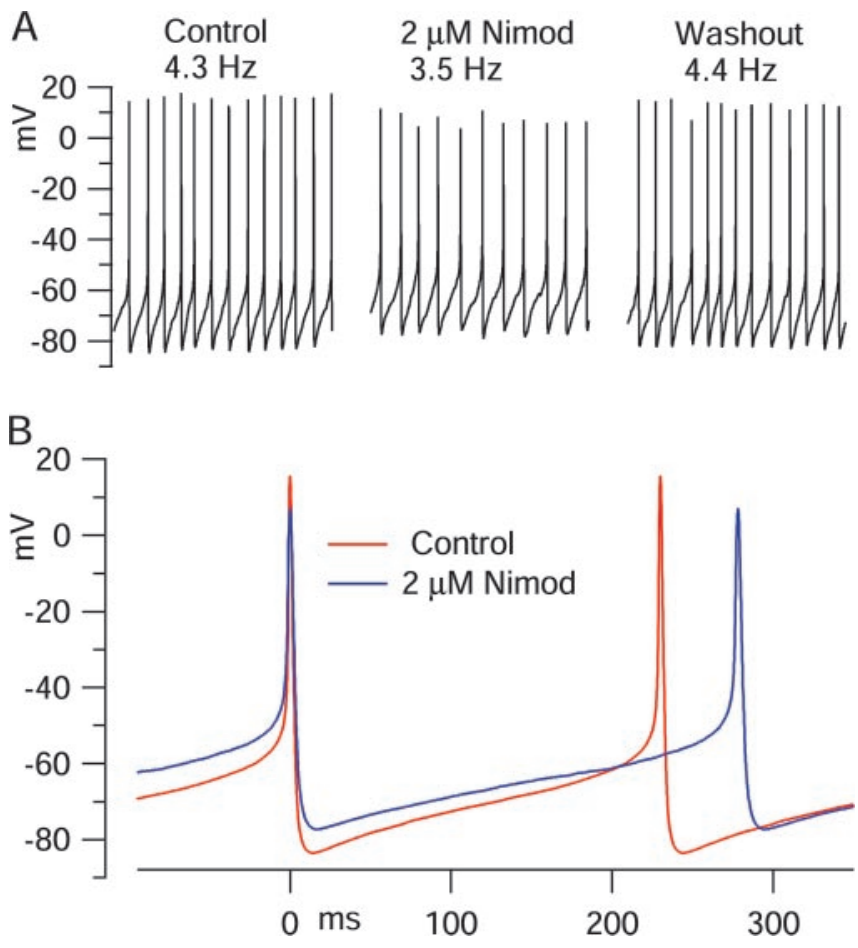

Figure 11. Effect of nimodipine on spontaneous firing. A, Three-second segments of spontaneous activity recorded in control (left), after 80 sec exposure to $2 \mu \mathrm{m}$ nimodipine (middle), and after $3 \mathrm{~min}$ of washing with control solution (right). B, Voltage trajectory in control (red) and with nimodipine (blue), signal averaged over 1 sec (aligned at spike peaks).

injected, firing became faster (albeit with reduced peaks and rate of rise) for net depolarizations of averaged voltage in the range produced by nimodipine (up to $6 \mathrm{mV}$ ). Only for much larger depolarizations did firing stop, and cessation of firing was preceded by increasingly rapid firing of increasingly small spikes rather than the slower firing usually seen with nimodipine.

The variable effects of nimodipine in different cells suggest complex effects as a result of blocking both inward calcium current and outward calcium-activated potassium current. We used the action potential clamp method to directly compare the timing and size of calcium current and calcium-activated potassium current during the pacemaking cycle (Fig. 12). The calciumactivated potassium current presumably includes components from both large-conductance calcium-activated potassium (BK) channels and small-conductance calcium-activated potassium channels, both known to be present in SCN neurons (Cloues and Sather, 2003; Teshima et al., 2003). BK channels appeared to carry most of the calcium-activated potassium current during spontaneous action potentials, because the calcium-activated potassium current deactivated very quickly during the falling phase of the action potential, consistent with steep voltage dependence of BK channels.

The sum of calcium current and calcium-activated potassium current was net inward immediately before the spike but was net outward and much larger during the falling phase of the spike. The calcium-activated potassium current sensitive to block by nimodipine typically comprised $\sim 30-50 \%$ of total calciumactivated potassium current, as in Figure 12. This is consistent with the results of Cloues and Sather (2003), who found that nimodipine reduced the afterhyperpolarization of SCN action potentials by $\sim 30 \%$. The sum of nimodipine-sensitive calcium current and nimodipine-sensitive calcium-activated potassium 


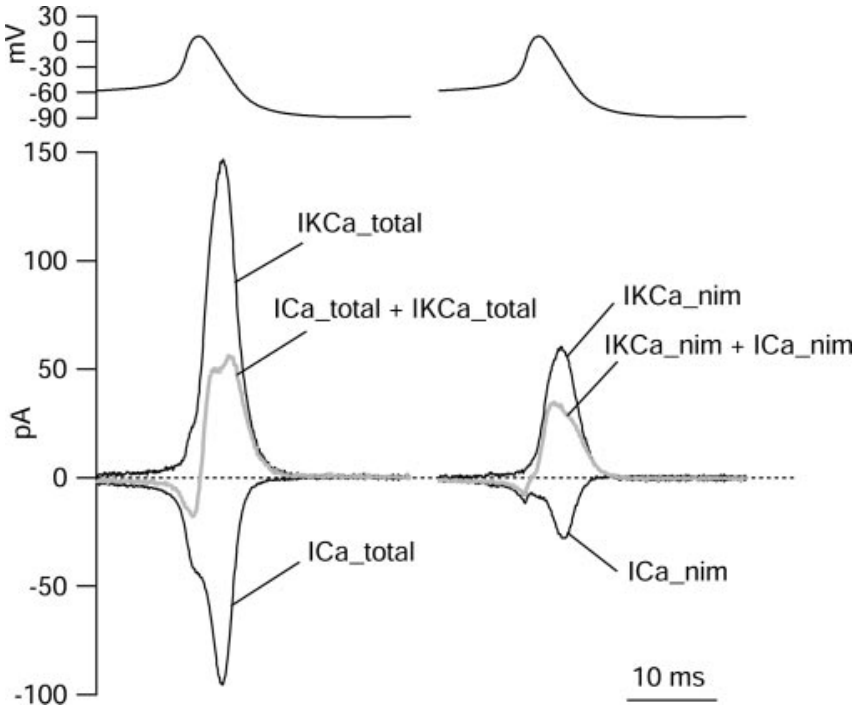

Figure 12. Calcium current and calcium-activated potassium current during spontaneous action potentials. Total calcium current and nimodipine-sensitive calcium current were determined as in Figure 10. In addition, calcium-activated potassium current was determined by first determining total potassium current as current blocked by $155 \mathrm{~mm}$ TEA (replacing $155 \mathrm{~mm} \mathrm{Na}$ ) starting with a background of Tyrode's solution containing $300 \mathrm{~nm} \mathrm{TTX,} \mathrm{then} \mathrm{determining} \mathrm{non-}$ Ca-dependent potassium current (performing the same replacement of $\mathrm{Na}$ by $155 \mathrm{~mm}$ TEA but using a pair of solutions in which $1.2 \mathrm{~mm} \mathrm{CaCl}$ was replaced by $1.2 \mathrm{~mm} \mathrm{CoCl}_{2}$ ) and then subtracting the two to yield calcium-activated potassium current. The sum of total calcium current and calcium-activated potassium current (gray trace; left) was net inward immediately before the spike but much larger and net outward during the falling phase of the spike. The sum of calcium current and calcium-activated potassium current could alternatively be determined as the net current sensitive to replacing $1.2 \mathrm{~mm} \mathrm{CaCl}$ with $1.2 \mathrm{~mm} \mathrm{CoCl}$ with a background of Tyrode's solution with $300 \mathrm{~nm}$ TTX; this gave a nearly identical current. The calcium-activated potassium current sensitive to block by nimodipine (i.e., that activated by nimodipine-sensitive calcium current) was determined by subtracting non-nimodipine-sensitive potassium current (determined by replacing $155 \mathrm{Na}$ with $155 \mathrm{~mm}$ TEA using a pair of solutions both containing 2 $\mu \mathrm{m}$ nimodipine) from total potassium current determined as above. The sum of nimodipinesensitive calcium current and nimodipine-sensitive calcium-activated potassium current (gray trace; right) was inward before the spike but net outward when integrated.

current (Fig. 12, gray trace; right) was inward before the spike but net outward when integrated over the entire firing cycle. In this cell, nimodipine-sensitive calcium current integrated over the firing cycle amounted to $-140 \mathrm{pA}-\mathrm{msec}$ (fC), and nimodipinesensitive calcium-activated potassium current amounted to +256 fC. Similar results were obtained in a total of six cells, in which integrated nimodipine-sensitive calcium current was $-138 \pm 48 \mathrm{fC}$, and nimodipine-sensitive calcium-activated potassium current was $+334 \pm 157 \mathrm{fC}$. The ratio of charge carried by nimodipine-sensitive calcium-activated potassium current to that carried by nimodipine-sensitive calcium current was $2.4 \pm$ $0.8(n=6)$.

These results show that the combination of nimodipinesensitive calcium current and calcium-activated potassium current consistently gives a net outward current when averaged across the whole firing cycle. This is consistent with the net average depolarization produced by nimodipine application and supports the idea that the depolarization is attributable, at least in part, to block of calcium-activated potassium current. The combination of nimodipine-sensitive calcium and calcium-activated potassium currents was net inward in the $10 \mathrm{msec}$ or so before the spike, and it is probably block of this current that is responsible for the modest slowing of firing most commonly seen with nimodipine. By itself, the net depolarization seen with nimodipine would probably speed firing somewhat, consistent with the ob-

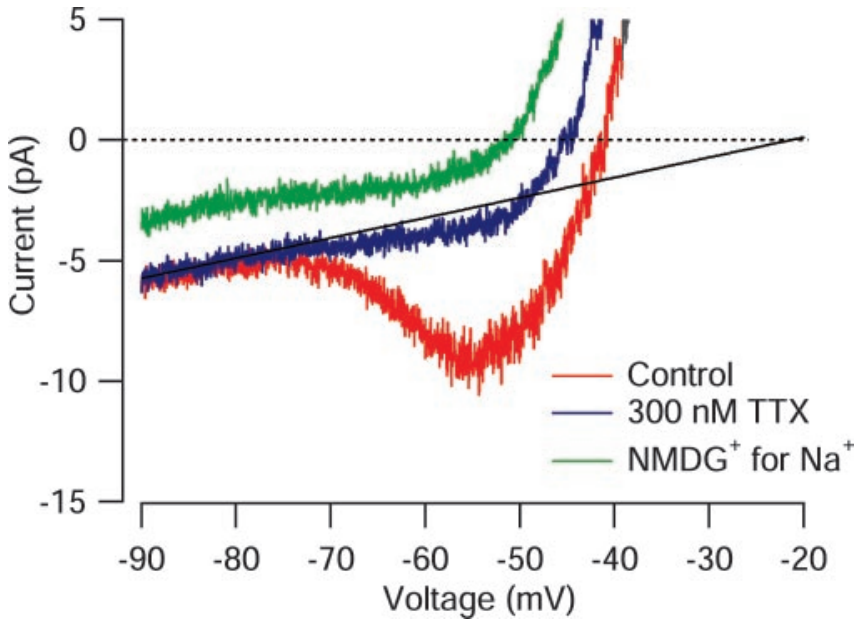

Figure 13. Background currents in the interspike voltage range. Measured steady-state currents in an $\mathrm{SCN}$ neuron. Current was measured in response to a ramp of voltage from -98 to $+12 \mathrm{mV}$ delivered at $20 \mathrm{mV} / \mathrm{sec}$, in control condition Tyrode's solution (red), after the addition of $300 \mathrm{~mm}$ TTX (blue) and after replacement of external Na ions by NMDG ions (with $300 \mathrm{~nm}$ TTX present in both solutions; green). The data shown were signal averaged over four to eight presentations of command. The solid line indicates linear fit to steady-state current in the presence of TTX between -90 and $-78 \mathrm{mV}$, extrapolated to other voltages.

servation that when this depolarization was largest, firing was speeded.

\section{Background currents in the interspike voltage range}

Some types of spontaneously active neurons appear to have resting potentials (measured when the cell is silenced by TTX) that are relatively depolarized (Raman et al., 2000; Eggerman et al., 2003). In principle, if the "resting" potential is depolarized with respect to the threshold for firing a spike, spontaneous firing might occur even in the absence of any subthreshold voltagedependent conductances. Even with resting potentials that are hyperpolarized with respect to threshold, the associated background conductances could help in the initial phases of spontaneous depolarization.

In spontaneously active dissociated SCN neurons, the average resting potential was $-55 \pm 10 \mathrm{mV}(n=35)$ for cells in which firing was stopped by application of TTX (i.e., cells that did not show prominent calcium-dependent oscillations in the presence of TTX) and was $-50 \pm 8 \mathrm{mV}(n=6)$ for cells that did show oscillations in TTX, when measured in the presence of both TTX and nimodipine to stop oscillations. The average input resistance of all cells (which was determined between -83 and $-78 \mathrm{mV}$, where no voltage-dependent conductances were present) was $9.5 \pm 4.1 \mathrm{G} \Omega(n=70)$. Thus, the cells have moderately depolarized resting potentials but very high input resistances.

The average resting potential of the cells is depolarized enough that during most of the interspike interval, the background conductance will pass inward (depolarizing) current and thus help generate the spontaneous depolarization. We characterized the background currents active at voltages corresponding to the interspike interval by using slow $(20 \mathrm{mV} / \mathrm{sec})$ ramps of voltage. In the example shown in Figure 13, with unaltered Tyrode's solution, the steady-state current-voltage relationship was approximately linear from -90 to $\sim-73 \mathrm{mV}$, and the slope corresponded to a resistance of $12.8 \mathrm{G} \Omega$. Positive to $-73 \mathrm{mV}$, the steady-state current showed a inward component from persistent sodium current that reached a peak near $-55 \mathrm{mV}$. Application of $300 \mathrm{~nm}$ TTX blocked this component but had no effect on the 
current negative to $-73 \mathrm{mV}$. The TTX-sensitive steady-state current had a steep voltage dependence, with a midpoint near -63 $\mathrm{mV}$ and a magnitude of $\sim 6 \mathrm{pA}$. The voltage dependence of activation of steady-state sodium current is comparable with that of the TTX-sensitive current flowing during interspike intervals during spontaneous firing (Fig. 6A), except that the interspike current continues to increase sharply positive to $-50 \mathrm{mV}$, where the steady-state current saturates; this reflects the fact that the depolarization during the interspike interval is much faster $(\sim 200 \mathrm{mV} / \mathrm{sec})$ and sodium current is far from being at a steady state.

For the currents shown in Figure 13, the steady-state current in the presence of TTX was zero at $-45 \mathrm{mV}$, which would thus correspond to the resting potential in an unclamped cell in the presence of TTX. Even in the presence of TTX, the shape of the steady-state current-voltage relationship was far from being ohmic below the resting potential. The behavior is better characterized as the sum of an ohmic component with slope $12.8 \mathrm{G} \Omega$ that has an extrapolated reversal potential near $-20 \mathrm{mV}$ (Fig. 13, solid line), together with a steeply voltage-dependent outward current, presumably from voltage-dependent potassium channels, that activates near $-50 \mathrm{mV}$. (There is also a small inflection of inward current between -60 and $-50 \mathrm{mV}$ that could plausibly reflect a small steady-state calcium current.) Without the component of an apparent steady-state voltage-dependent potassium current, the resting potential of the cell in TTX would evidently be near $-20 \mathrm{mV}$. In collected results, the average reversal potential of background conductance extrapolated by a linear fit to the steady-state current in the range -95 to $-75 \mathrm{mV}$ was $-29 \pm 12 \mathrm{mV}(n=7)$. The slope of the linear fit in these cells was $11 \pm 3 \mathrm{G} \Omega$.

These results suggest that if distinguished from voltagedependent potassium current (which appears important for setting resting potential), the background conductance in dmSCN neurons reverses near $-30 \mathrm{mV}$, quite far from the potassium equilibrium potential and suggestive of a significant resting sodium permeability. To further explore the properties of background conductance in the cells, we tested the effect of replacing external sodium ions by NMDG, a large cation that is impermeant in many channels (and transporters) that carry sodium ions. When sodium was replaced by NMDG in the presence of TTX (Fig. 13, green trace), the current at all voltages shifted outward and the zero-current voltage shifted from -45 to $-51 \mathrm{mV}$. Similar results were obtained in six cells, with an outward shift of 2-4 pA after NMDG replacement of sodium.

Figure 14 summarizes collected results from the experiments that determined relative magnitudes of various inward currents during the interspike interval. The top panel shows membrane voltage during the pacemaking cycle of an SCN neuron that had typical parameters for rate of firing $(8 \mathrm{~Hz})$, peak of action potentials $(+24 \mathrm{mV})$, and voltage at afterhyperpolarization $(-79 \mathrm{mV})$. Plotted below is mean interspike sodium current and calcium current (averaged from value for 13 cells, from Fig. 6), along with the current expected from a background conductance corresponding to a slope of $9.5 \mathrm{G} \Omega$ and reversal potential of $-29 \mathrm{mV}$, the mean values estimated from experiments like those in Figure 13. The comparison shows that background current provides most of the inward current in the first phase of spontaneous depolarization, from the afterhyperpolarization $(-85$ to -80 $\mathrm{mV}$ ) up to $\sim-60 \mathrm{mV}$. Positive to $-60 \mathrm{mV}$, TTX-sensitive sodium current provides the major depolarizing drive, and because of its steep-voltage dependence becomes, by far, the dominant current between $-60 \mathrm{mV}$ and threshold. These inward currents are likely to be opposed by outward currents through potassium
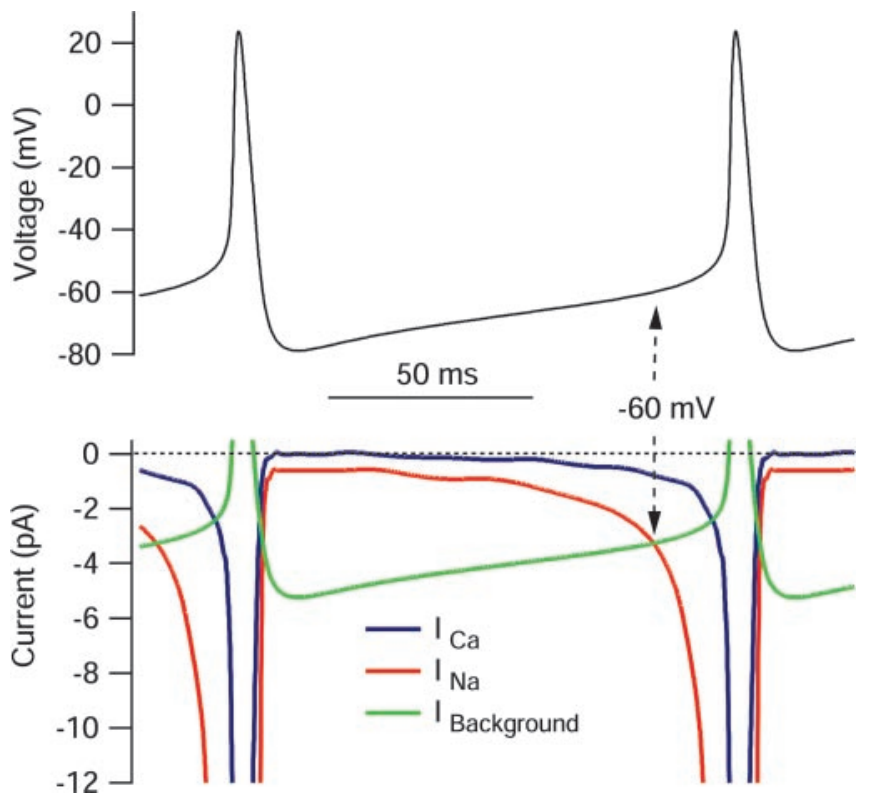

Figure 14. Summary of inward currents driving spontaneous depolarization. Top, Voltage during the cycle of spontaneous firing in a cell with typical parameters $(8 \mathrm{~Hz}$; peak, $+24 \mathrm{mV}$; trough, $-79 \mathrm{mV}$ ), averaged over 80 cycles. Bottom, Population-averaged interspike sodium current (red), interspike calcium current (blue), and predicted background current (green). For each voltage during the interspike depolarization, the value of mean sodium current and mean calcium current was read off from smooth fits (cubic spline) to the mean interspike sodium and calcium currents plotted in Figure 6 . The background current is based on an ohmic conductance with the slope corresponding to $9.5 \mathrm{G} \Omega$ (the mean measured in 70 cells) and the mean reversal potential of $-29 \mathrm{mV}$ estimated from linear fits to background current in the range -95 to $-75 \mathrm{mV}$.

channels, which remain to be characterized. The apparent voltage-activated potassium current evoked positive to $-50 \mathrm{mV}$ by slow ramps may originate from A-type potassium channels, which are present in SCN neurons (Huang et al., 1993) and activate as negative as -60 to $-50 \mathrm{mV}$ (Bouskila and Dudek, 1995; Walsh et al., 1995), or possibly from steady-state calciumactivated potassium current and could play a role in modulating spontaneous firing.

\section{Discussion}

Our results show that the spontaneous interspike depolarization of dissociated SCN neurons is attributable primarily to TTXsensitive sodium current that flows at subthreshold voltages, together with background conductances that result in a depolarized resting potential. The initial phase of spontaneous depolarization, from $\sim-80$ to $-60 \mathrm{mV}$, is attributable mainly to current from the background conductance, along with a small amount of current from TTX-sensitive sodium channels. In the later phase of depolarization, from $-60 \mathrm{mV}$ to spike threshold, TTXsensitive sodium current plays the dominant role. In addition, L-type calcium current makes a small contribution by producing net inward current late in the interspike interval.

\section{Nature of subthreshold TTX-sensitive sodium current}

Our results using the action potential clamp method with spontaneously firing neurons support previous suggestions of the important involvement of subthreshold sodium current in spontaneous firing of SCN neurons (Pennartz et al., 1997; Kononenko et al., 2004). The nature of this current and its relationship to the transient sodium current underlying spikes remain to be clarified. Previous work classified the subthreshold sodium current as 
a slowly inactivating component of sodium current distinguishable from both conventional fast-inactivating sodium current and from persistent noninactivating sodium current (Pennartz et al., 1997; Kononenko et al., 2004). However, in principle, all three could originate from a single population of channels because some models of sodium channel gating kinetics predict slow and incomplete inactivation of macroscopic current for depolarizations to subthreshold voltages (Taddese and Bean, 2002).

\section{Calcium channel-dependent oscillations}

Just as for intact dmSCN neurons in brain slice (Pennartz et al., 2002), dissociated neurons are capable of generating spontaneous nimodipine-sensitive oscillations in the presence of TTX.

However, our results argue against the idea that these oscillations comprise a generator potential for normal pacemaking, because calcium current accounts for only a small fraction of the net inward current driving pacemaking, even in cells showing robust oscillations in TTX. Thus, the oscillations mediated by calcium channels in the presence of TTX appear to be a distinct kind of activity from normal pacemaking, occurring at considerably more depolarized voltages and with a lower characteristic frequency.

As reported previously (Pennartz et al., 2002), we found that L-type calcium channels in dmSCN neurons have an unusually negative range of activation. Similar low-threshold nimodipinesensitive calcium current has previously been identified in hippocampal CA3 pyramidal neurons (Avery and Johnston, 1996) and in midbrain dopaminergic neurons (Durante et al., 2004). Such currents may be carried by $\mathrm{Ca}_{\mathrm{v}} 1.3\left(\alpha_{1 \mathrm{D}}\right)$ channels, which in heterologous expression systems activate at more negative voltages than $\mathrm{Ca}_{\mathrm{v}} 1.2\left(\alpha_{1 \mathrm{C}}\right)$ channels (Koschak et al., 2001; $\mathrm{Xu}$ and Lipscombe, 2001), the other type of calcium channel carrying L-type current in neurons. Current through calcium channels activated by small depolarizations would be less opposed by potassium current through BK channels, which are steeply voltage dependent; such calcium channels are well suited for initiating the oscillations occurring in TTX, helping to explain why nimodipine was usually effective in blocking these, although nimodipine-sensitive channels comprise only $\sim 30 \%$ of the overall calcium current.

\section{Resting potential and background conductance}

A striking feature of the dissociated $\mathrm{dmSCN}$ neurons is their extremely high input resistance (mean, $9 \mathrm{G} \Omega$ ), together with their relatively depolarized resting potentials (typically near -55 to $-50 \mathrm{mV}$ ) when firing is stopped by the combination of TTX and nimodipine. The initial phase of spontaneous depolarization of SCN neurons appears to be mainly relaxation of the membrane potential back toward the resting potential. However, if there were not also subthreshold sodium current, which makes a much larger contribution positive to $-60 \mathrm{mV}$, pacemaking would be much slower or possibly prevented by the component of voltagedependent potassium current that activates steeply positive to $-50 \mathrm{mV}$, near spike threshold.

Most types of neurons have resting potentials considerably depolarized to the potassium equilibrium potential, but the understanding of conductances that determine resting potentials is still limited. The outward shift of resting currents on replacing $\mathrm{Na}^{+}$with $\mathrm{NMDG}^{+}$is consistent with a resting sodium conductance (with TTX present), similar to previous results in deep cerebellar nuclear cells (Raman et al., 2000) and orexinergic neurons (Eggermann et al., 2003). The outward shift of currents after $\mathrm{Na}^{+}$removal could also represent enhancement of an outward
$\mathrm{Na} / \mathrm{K}$ ATPase electrogenic pump current (owing to reduction of the sodium gradient) or elimination of $\mathrm{Na} / \mathrm{Ca}$ exchanger current. Participation of $\mathrm{Na} / \mathrm{Ca}$ exchanger currents in pacemaking of cardiac sinoatrial cells has been suggested (Bogdanov et al., 2001; Kurata et al., 2002). However, the current seen when replacing $\mathrm{Na}^{+}$by NMDG ${ }^{+}$was similar when measured using voltage steps confined to voltages $<-70 \mathrm{mV}$, in which little calcium entry would occur, and intracellular calcium should be buffered to low steady-state values by the $0.9 \mathrm{~mm}$ EGTA in the internal solution.

\section{Pacemaking in dissociated versus intact neurons}

For determining the mechanism of pacemaking, dissociated neurons have the unique advantage of allowing current-clamp experiments to be combined with voltage-clamp experiments that are sufficiently accurate to permit characterization of fast voltagedependent currents. Also, the fast solution exchange possible for dissociated neurons facilitates isolation of multiple individual currents. However, a disadvantage of dissociated cells is the loss of whatever relevant channels may be present in dendrites or the axon. For example, if calcium channels are enriched in dendrites of dmSCN neurons, they may play a greater role in pacemaking of intact compared with dissociated neurons. Consistent with this possibility, nimodipine appears to slow firing more in intact cells [ 30\% (Pennartz et al., 2002), 20\% (Cloues and Sather, 2003)] than we found for dissociated cells $(\sim 8 \%)$. On the other hand, the dissociated neurons retain the capability of generating calcium-dependent oscillations in TTX, which seem identical to those in slice (Pennartz et al., 2002), arguing that any loss of calcium current cannot be very profound. Peak step-evoked calcium current in dissociated cells was smaller $(-120 \pm 41 \mathrm{pA} ; n=$ $\left.12 ; 1.2 \mathrm{mM} \mathrm{Ca}^{2+}\right)$ than for cells in brain slice $(-400 \pm 42 \mathrm{pA} ; 2.5$ $\mathrm{mM} \mathrm{Ca}^{2+}$ ) (Pennartz et al., 2002), but considering the difference in $\mathrm{Ca}^{2+}$ concentration and the smaller size of the dissociated cells $(5.2 \pm 1.4 \mathrm{pF} ; n=68)$ compared with cells in slice $(10 \pm 1 \mathrm{pF})$ (Pennartz et al., 2002), the density of calcium current seems comparable. Also, the spontaneous firing of dissociated cells is actually slightly faster than intact cells, arguing against the likelihood that channels in dendrites are crucial for the basic engine of pacemaking.

Another concern about the physiological fidelity of dissociated cells is the possibility that a significant nonphysiological leak conductance could be induced by damage during dissociation or from leak around the pipette (the latter not unique to dissociated cells). However, any such leak pathways must be minimal considering the very high input resistance of the cells (averaging 9 $\mathrm{G} \Omega$, including any contribution from leak around the pipette) and the fact that much of the inward background current was eliminated by replacement of $\mathrm{Na}^{+}$by $\mathrm{NMDG}^{+}$, which would not be expected for holes in the membrane or leak around the pipette.

\section{Implications for day-night variation in firing frequency}

The cells we studied were taken from animals during the middle of daytime and showed both the relatively rapid firing and nimodipine-sensitive oscillations in TTX typical of dmSCN cells in brain slices taken from daytime animals (Pennartz et al., 2002). Nevertheless, calcium current makes only a minor contribution to pacemaking under our conditions, and even complete block of nimodipine-sensitive calcium current produced only a minor change in firing frequency. Thus, even if calcium current contributes somewhat more to pacemaking in intact cells at physiological temperature, the diurnal variation in calcium current discovered by Pennartz et al. (2002), with nighttime levels approximately half of daytime levels, seems likely to account for 
only a little of the more than threefold reduction in the firing rate at nighttime compared with daytime (Pennartz et al., 2002). Perhaps the diurnal variation in calcium current is important for other functional roles of calcium current, such as supporting release of transmitters or calcium-dependent gene expression. Because calcium-activated potassium current strongly dominates over calcium current, except immediately before spikes, one predicted electrical consequence of a larger calcium current during the daytime is more rapid repolarization of action potentials and more prominent afterhypolarizations, as is seen (Schaap et al., 1999; Pennartz et al., 2002).

The high input resistance of the cells and relatively depolarized reversal potential of the background conductance suggests that the resting potassium conductance of the cells is unusually low. De Jeu et al. (1998) and Pennartz et al. (2002) found that SCN neurons studied during the day have both more depolarized resting potentials and higher input resistances than those studied during the night. Thus, cells apparently have a larger resting potassium conductance during the night. Our results suggest that this difference is probably more significant than the difference in voltage-dependent calcium conductance for determining diurnal changes in firing frequency. Also, pacemaking frequency is likely to be strongly influenced by the magnitude of both subthreshold TTX-sodium current and an unidentified voltage-dependent potassium current that activates steeply near $-50 \mathrm{mV}$. Possible diurnal changes in these and other voltage-dependent channels remain to be examined.

\section{References}

Akasu T, Shoji S, Hasuo H (1993) Inward rectifier and low-threshold calcium currents contribute to the spontaneous firing mechanism in neurons of the rat suprachiasmatic nucleus. Pflügers Arch 425:109-116.

Avery RB, Johnston D (1996) Multiple channel types contribute to the lowvoltage-activated calcium current in hippocampal CA3 pyramidal neurons. J Neurosci 16:5567-5582.

Bennett BD, Callaway JC, Wilson CJ (2000) Intrinsic membrane properties underlying spontaneous tonic firing in neostriatal cholinergic interneurons. J Neurosci 20:8493-88503.

Bogdanov KY, Vinogradova TM, Lakatta EG (2001) Sinoatrial nodal cell ryanodine receptor and $\mathrm{Na}(+)-\mathrm{Ca}(2+)$ exchanger: molecular partners in pacemaker regulation. Circ Res 88:1254-1258.

Bouskila Y, Dudek FE (1995) A rapidly activating type of outward rectifier $\mathrm{K}+$ current and A-current in rat suprachiasmatic nucleus neurones. J Physiol (Lond) 488:339-350.

Brumberg JC, Nowak LG, McCormick DA (2000) Ionic mechanisms underlying repetitive high-frequency burst firing in supragranular cortical neurons. J Neurosci 20:4829-4843.

Buijs RM, Swaab DF, Dogterom J, van Leeuwen FW (1978) Intra- and extrahypothalamic vasopressin and oxytocin pathways in the rat. Cell Tissue Res 186:423-433.

Cloues RK, Sather WA (2003) Afterhyperpolarization regulates firing rate in neurons of the suprachiasmatic nucleus. J Neurosci 23:1593-1604.

Crill WE (1996) Persistent sodium current in mammalian central neurons. Annu Rev Physiol 58:349-362.

de Haas V, Vogel W (1989) Sodium and potassium currents recorded during an action potential. Eur Biophys J 17:49-51.

de Jeu MTG, Pennartz CMA (1997) Functional characterization of the $\mathrm{H}$-current in SCN neurons in subjective day and night: a whole-cell patch-clamp study in acutely prepared brain slices. Brain Res 767:72-80.

de Jeu MTG, Hermes M, Pennartz CMA (1998) Circadian modulation of membrane properties in slices of rat suprachiasmatic nucleus. NeuroReport 9:3725-3729.

Derambure PS, Boulant JA (1994) Circadian thermosensitive characteristics of suprachiasmatic neurons in vitro. Am J Physiol Regul Integr Comp Physiol 266:R1876-R1884.

Do MT, Bean BP (2003) Subthreshold sodium currents and pacemaking of subthalamic neurons. Modulation by slow inactivation. Neuron 39:109-120.
Durante P, Cardenas CG, Whittaker JA, Kitai ST, Scroggs RS (2004) Lowthreshold L-type calcium channels in rat dopamine neurons. J Neurophysiol 91:1450-1454.

Eggermann E, Bayer L, Serafin M, Saint-Mleux B, Bernheim L, Machard D, Jones BE, Muhlethaler M (2003) The wake-promoting hypocretinorexin neurons are in an intrinsic state of membrane depolarization. J Neurosci 23:1557-1562.

Gillette MU, Tischkau (1999) Suprachiasmatic nucleus: the brain's circadian clock Recent Prog Horm Res 54:35-58.

Green DJ, Gillette R (1982) Circadian rhythm of firing rate recorded from single cells in the rat suprachiasmatic brain slice. Brain Res 245:198-200.

Hamada T, LeSauter J, Venuti JM, Silver R (2001) Expression of period genes: rhythmic and nonrhythmic compartments of the suprachiasmatic nucleus pacemaker. J Neurosci 21:7742-7750.

Huang RC (1993) Sodium and calcium currents in acutely dissociated neurons from rat suprachiasmatic nucleus. J Neurophysiol 70:1692-1703.

Huang RC, Peng YW, Yau KW (1993) Zinc modulation of a transient potassium current and histochemical localization of the metal in neurons of the suprachiasmatic nucleus. Proc Natl Acad Sci USA 90:11806-11810.

Inouye ST, Kawamura H (1979) Persistence of circadian rhythmicity in a mammalian hypothalamic "island" containing the suprachiasmatic nucleus. Proc Natl Acad Sci USA 76:5962-5966.

Jac M, Sumova A, Illnerova H (2000) c-Fos rhythm in subdivisions of the rat suprachiasmatic nucleus under artificial and natural photoperiods. Am J Physiol Regul Integr Comp Physiol 279:R2270-R2276.

Jones HC, Keep RF (1988) Brain fluid calcium concentration and response to acute hypercalcemia during development in rat. J Physiol (Lond) 402:579-593

King DP, Takahashi JS (2000) Molecular genetics of circadian rhythms in mammals. Ann Rev Neurosci 23:713-742.

Kononenko NI, Dudek FE (2004) Mechanism of irregular firing of suprachiasmatic nucleus neurons in rat hypothalamic slices. J Neurophysiol 91:267-273

Kononenko NI, Shao LR, Dudek FE (2004) Riluzole-sensitive slowly inactivating sodium current in rat suprachiasmatic nucleus neurons. J Neurophysiol 91:710-718.

Koschak A, Reimer D, Huber I, Grabner M, Glossmann H, Engel J, Striessnig J (2001) $\alpha 1 \mathrm{D}$ (Cav1.3) subunits can form L-type $\mathrm{Ca}^{2+}$ channels activating at negative voltages. J Biol Chem 276:22100-22106.

Kurata Y, Hisatome I, Imanishi S, Shibamoto T (2002) Dynamical description of sinoatrial node pacemaking: improved mathematical model for primary pacemaker cell. Am J Physiol Heart Circ Physiol 283:H2074-H2101.

Leak RK, Moore RY (2001) Topographic organization of suprachiasmatic nucleus projection neurons. J Comp Neurol 433:312-334.

Llinás R, Sugimori M, Simon SM (1982) Transmission by presynaptic spike-like depolarization in the squid giant synapse. Proc Natl Acad Sci USA 79:2415-2419.

Magistretti J, Mantegazza M, Guatteo E, Wanke E (1996) Action potentials with patch-clamp amplifiers: are they genuine? Trends Neurosci 12:530-534.

Manthei RC, Wricht DC, Kenny AD (1973) Altered CSF constituents and retrograde amnesia in rats: a biochemical approach. Physiol Behav 10:517-521.

Moga MM, Moore RY (1997) Organization of neural inputs to the suprachiasmatic nucleus in the rat. J Comp Neurol 389:508-534.

Moore RY (1983) Organization and function of a central nervous system circadian oscillator: the suprachiasmatic hypothalamic nucleus. Fed Proc 42:2783-2789.

Moore RY (1996) Entrainment pathways and the functional organization of the circadian system. Prog Brain Res 111:103-119.

Moore RY, Speh JC, Leak RK (2002) Suprachiasmatic nucleus organization. Cell Tissue Res 309:89-98.

Neher E (1992) Correction for liquid junction potentials in patch clamp experiments. Methods Enzymol 207:123-131.

Panda S, Hogenesch JB, Kay SA (2002) Circadian rhythms from flies to human. Nature 417:329-335.

Pennartz CM, Bos NP, Jeu MT, Geurtsen AM, Mirmiran M, Sluiter AA, Buijs RM (1998a) Membrane properties and morphology of vasopressin neurons in slices of rat suprachiasmatic nucleus. J Neurophysiol 80:2710-2717.

Pennartz CMA, Bierlaagh MA, Geurtsen AMS (1997) Cellular mechanisms 
underlying spontaneous firing in rat suprachiasmatic nucleus: Involvement of a slowly inactivating component of sodium current. J Neurophysiol 78:1811-1825.

Pennartz CMA, de Jeu MTG, Geurtsen AMS, Sluiter AA, Hermes MLHJ (1998b) Electrophysiological and morphological heterogeneity of neurons in slices of rat suprachiasmatic nucleus. J Physiol (Lond) 506:775-793.

Pennartz CMA, de Jeu MTG, Bos NPA, Schaap J, Geurtsen AMS (2002) Diurnal modulation of pacemaker potentials and calcium current in the mammalian circadian clock. Nature 416.286-290.

Raman IM, Gustafson AE, Padgett D (2000) Ionic currents and spontaneous firing in neurons isolated from the cerebellar nuclei. J Neurosci 20:9004-9016.

Reppert SM, Weaver DR (2001) Molecular analysis of mammalian circadian rhythms. Annu Rev Physiol 63:647-676.

Schaap J, Bos NPA, de Jeu MTG, Geurtsen AMS, Meijer JH, Pennartz CMA (1999) Neurons of the suprachiasmatic nucleus show a circadian rhythm in membrane properties that is lost during prolonged whole-cell recording. Brain Res 815:154-166.

Shibata S, Oomura Y, Liou SY, Ueki S (1984) Electrophysiological studies of the development of suprachiasmatic neuronal activity in hypothalamic slice preparations. Brain Res 315:29-35.

Taddese A, Bean BP (2002) Subthreshold sodium current from rapidly in- activating sodium channels drives spontaneous firing of tuberomammillary neurons. Neuron 33:587-600.

Teshima K, Kim SH, Allen CN (2003) Characterization of an apaminsensitive potassium current in suprachiasmatic nucleus neurons. Neuroscience 120:65-73.

van den Pol AN (1980) The hypothalamic suprachiasmatic nucleus of rat: intrinsic anatomy. J Comp Neurol 191:661-702.

van den Pol AN, Tsujimoto KL (1985) Neurotransmitters of the hypothalamic suprachiasmatic nucleus: immunocytochemical analysis of 25 neuronal antigens. Neuroscience 15:1049-1086.

Walsh IB, van den Berg RJ, Rietveld WJ (1995) Ionic currents in cultured rat suprachiasmatic nucleus. Neuroscience 69:915-929.

Welsh DK, Logothetis DE, Meister M, Reppert SM (1995) Individual neurons dissociated from rat suprachiasmatic nucleus express independently phased circadian firing rhythms. Neuron 14:697-706.

Xu W, Lipscombe D (2001) Neuronal Ca(V)1.3 $\alpha$ (1) L-type channels activate at relatively hyperpolarized membrane potentials and are incompletely inhibited by dihydropyridines. J Neurosci 21:5944-5951.

Zaza A, Micheletti M, Brioschi A, Rocchetti M (1997) Ionic currents during sustained pacemaker activity in rabbit sino-atrial myocytes. J Physiol (Lond) 505:677-688. 